Marcelo Mella, Héctor Ríos, Ricardo Rivera, Condiciones orgánicas y correlaciones de fuerza del movimiento estudiantil chileno. Una aproximación desde la Confech (2011-2015) / Organic conditions and strength correlations of chilean student movement. An approach from Confech (2011-2015), Revista Izquierdas, 27, abril 2016, ISSN 0718-5049, pp. 124-160

\title{
Condiciones orgánicas y correlaciones de fuerza del movimiento estudiantil chileno. Una aproximación desde la Confech (2011- 2015)
}

\section{Organic conditions and strength correlations of chilean student movement. An approach from Confech (2011-2015)}

\author{
Marcelo Mella Polanco ** \\ Héctor Ríos Jara ${ }^{* * *}$ \\ Ricardo Rivera Gallardo ${ }^{* * * *}$
}

\footnotetext{
* Este artículo es parte de un programa de investigación orientado al análisis del movimiento estudiantil universitario chileno durante el período 2010 a 2015, a partir de la composición de la Confederación de Estudiantes de Chile. La secuencia de trabajos y publicaciones abordará tres aspectos de este actor: en primer lugar, a través de una mirada a nivel nacional de las principales tendencias en el espacio CONFECH; en segundo término, se indagará acerca de las correlaciones de fuerza en el Pleno durante esta fase del proceso político chileno; y, finalmente, se analizará la gobernanza de la Mesa Ejecutiva de la Multifederativa. Elaborado en el marco del proyecto FONDECYT Regular, código 1130323

** Académico Departamento de Historia, Universidad de Santiago de Chile; Doctor en Estudios Americanos, Instituto de Estudios Avanzados, Universidad de Santiago de Chile; Magíster en Ciencia Política, Instituto de Asuntos Públicos, Universidad de Chile; Licenciado en Historia, Universidad Católica de Valparaíso. Email: marcelo.mella@usach.cl

${ }^{* * *}$ Psicólogo Social, Universidad de Santiago de Chile, hector.rios@usach.cl

Periodista, Universidad de Santiago de Chile. Estudiante de Magister en Medios, Comunicación y Cultura, Universidad Autónoma de Barcelona, ricardo.rivera.gallardo@gmail.com
} 
Marcelo Mella, Héctor Ríos, Ricardo Rivera, Condiciones orgánicas y correlaciones de fuerza del movimiento estudiantil chileno. Una aproximación desde la Confech (2011-2015) / Organic conditions and strength correlations of chilean student movement. An approach from Confech (2011-2015), Revista Izquierdas, 27, abril 2016, ISSN 0718-5049, pp. 124-160

\section{Resumen:}

El presente trabajo tiene como objetivo analizar las transformaciones orgánicas de la Confederación de Estudiantes de Chile (CONFECH) en el período 2011 a 2015 y las complejidades de su proceso de institucionalización en el contexto del gobierno de Sebastián Piñera y la posterior administración de Michelle Bachelet. Se argumenta, que los procesos de crecimiento y fragmentación del espacio CONFECH ha generado un aumento en los costos de la toma de decisiones y la coordinación colectiva que ha complejizado la capacidad de gestión política de la Mesa Ejecutiva.

Palabras clave: movimiento estudiantil, política chilena, conflicto social, reformas sectoriales, democratización.

Recibido: 18 diciembre 2015

Aceptado: 8 febrero 2016

\begin{abstract}
:
This paper aims at analyzing the organizational changes in the Confederation of Chilean Students (CONFECH) in the period 2011-2015 and the complexities of the process of institutionalization in the context of the government of Sebastián Piñera and the subsequent administration of Michelle Bachelet. It argues, in the main, that the processes of growth and fragmentation of space CONFECH have generated an increase in the cost of decision-making and collective coordination has become more complex political management capacity of the Executive Board.

Keywords: student movement, chilean policy, social conflict, sectoral reforms, democratization.
\end{abstract}

\section{Introducción}

El presente artículo tiene como objetivo analizar las transformaciones orgánicas de la Confederación de Estudiantes de Chile (CONFECH) entre 2011-2015 y las complejidades de su proceso de institucionalización en el contexto del gobierno de Sebastián Piñera (2010-2013) y los primeros años de la administración de Michelle Bachelet (2014-2015). Para ello, se explora la relación entre las condiciones orgánicas de este espacio y las correlaciones de fuerza resultantes, en cada año, durante el período en estudio.

Los movimientos sociales constituyen uno de los fenómenos políticos más complejos de analizar en las democracias contemporáneas. ${ }^{1} \mathrm{Su}$ facultad para constituirse en actor desafiante frente a los actores tradicionales y para permear la agenda política, la diversidad en sus repertorios estratégicos e ideológicos de acción y su capacidad para movilizar agentes marginales del espacio político formal, constituyen características que los transforma en fenómenos dinamizadores de las estructuras políticas institucionales. ${ }^{2}$

\footnotetext{
${ }^{1}$ Benjamín Tejerina. "Movimientos sociales, espacio público y ciudadanía: Los caminos de la utopía". Revista Crítica de Ciencias Sociales, 72, Octubre de 2005, 67-97. Chales Tilly, \& Lesley Wood. "Los movimientos sociales. 1768 - 2008. Desde sus orígenes a Facebook”. Barcelona, Critica, 2013.

${ }^{2}$ Alain Touraine. "Los movimientos sociales". Revista Colombiana de Sociología, 27, 2006, 255-278.
} 
Marcelo Mella, Héctor Ríos, Ricardo Rivera, Condiciones orgánicas y correlaciones de fuerza del movimiento estudiantil chileno. Una aproximación desde la Confech (2011-2015) / Organic conditions and strength correlations of chilean student movement. An approach from Confech (2011-2015), Revista Izquierdas, 27, abril 2016, ISSN 0718-5049, pp. 124-160

En el contexto latinoamericano, han representado un importante impulso de las democracias, interviniendo como actores estratégicos para la instalación o caída de gobiernos desde la década de 1980. En este sentido, abundante literatura ha analizado el papel de los movimientos sociales y "coaliciones callejeras", tanto como factores impulsores de nuevas fórmulas representativas, como en la oposición de gobiernos. ${ }^{3}$

Para el caso de Chile, los movimientos sociales corresponden a una manifestación histórica de larga data, que habiendo sido fundamental para direccionar los grandes cambios del siglo veinte, se mantuvo en un plano marginal durante los primeros gobiernos de la Concertación. ${ }^{4} \mathrm{Si}$ bien, en estos años iniciales de la democracia post-autoritaria se verificaron algunas movilizaciones de sectores de trabajadores, no fue sino hasta mediados de la primera década del 2000 cuando los movimientos sociales se articularon como actores con mayor incidencia en el sistema institucional. ${ }^{5}$

Como argumenta Gerardo Munk, los desarrollos evolutivos de los movimientos sociales requieren satisfacer, al mismo tiempo, las demandas estratégicas de la acción colectiva asociadas a consecución de resultados políticos y las demandas identitarias, focalizadas en la autonomía y autoafirmación de la acción colectiva frente a sus aliados y contendores situados en el campo de la política institucional. ${ }^{6}$ Esta dicotomía exige que los movimientos sociales puedan resolver la tensión entre legitimidad y efectividad, sin perder la condición de agente impulsor de procesos de cambio. Durante la fase 2011-15, sobrevienen diferentes momentos en la trayectoria del movimiento estudiantil chileno, en los que fue necesario reconstruir equilibrios virtuosos entre su dimensión identitaria, destinada a mantener su autonomía y su dimensión estratégica, destinada a maximizar su incidencia política.

\footnotetext{
${ }^{3}$ Desde una perspectiva politológica existe abudante producción sobre el tema. Para mayor referencia, véase: Aníbal Pérez-Liñán. "Instituciones, coaliciones callejeras e inestabilidad política: perspectivas teóricas sobre las crisis presidenciales". América Latina Hoy, 49, 2008. 105-126. José Antonio Cheibub. "Minority Governments, Deadlock Situations, and the Survival of Presidential Democracy". Comparative Political Studies, 35 (3), 2002, 284-312. Alejandro Bonvecchi. "Determinismo y contingencia en las interpretaciones políticas de la crisis Argentina". Revista SAAP, 2 (3), 2006, 509-536. Kathryn Hochstetler. "Repensando el presidencialismo: desafíos y caídas presidenciales en Sudamérica". América Latina Hoy, 49, 2008, 51-72.

${ }^{4}$ Gabriel Salazar. Movimientos sociales en Chile. Santiago, Uqbar editores, 2012. Tomás Moulian. Chile Actual. Anatomía de un mito. Santiago, LOM, 2002.

${ }^{5}$ Gabriel Salazar, op.cit. Tomás Moulian. op.cit. Mario Garcés. El despertar de la sociedad. Santiago, LOM ediciones. 2012. Giorgio Boccardo y Carlos Ruiz. "Problemas sociales de la concentración económica (visto desde la crisis)". Revista Análisis, 12, Departamento de Sociología de la Universidad de Chile, Santiago, 2009, 31-54. Giorgio Boccardo y Carlos Ruiz. "Peripecias del capital y el trabajo en el neoliberalismo avanzado". Revista Análisis, 15, Departamento de Sociología de la Universidad de Chile, 2012, 25-52. Alberto Mayol y Carla Azócar. "Politización del malestar, movilización social y transformación ideológica: el caso Chile 2011". Polis, 10, Santiago, 2011, 163-184. Alberto Mayol. No al Lucro. De la crisis del modelo a la nueva era política. Santiago, Debate. 2012.

${ }^{6}$ Gerardo Munck. "Algunos problemas conceptuales en el estudio de los movimientos sociales". Revista Mexicana de Sociología, Vol. 57, No. 3. Jul. - Sep., 1995, 17-40.
} 
Marcelo Mella, Héctor Ríos, Ricardo Rivera, Condiciones orgánicas y correlaciones de fuerza del movimiento estudiantil chileno. Una aproximación desde la Confech (2011-2015) / Organic conditions and strength correlations of chilean student movement. An approach from Confech (2011-2015), Revista Izquierdas, 27, abril 2016, ISSN 0718-5049, pp. 124-160

El análisis de esta singularidad plantea tres preguntas para este estudio. Primero ¿Cuáles son las principales transformaciones orgánicas y políticas al interior del espacio CONFECH desde el 2011? Segundo, ¿Cómo se relaciona los cambios en las correlaciones de fuerza entre los diferentes referentes políticos del movimiento con la gobernanza de este espacio? Tercero, ¿Cómo afecta la mayor centralidad política de la problemática educacional en Chile la autonomía o heteronomía del movimiento? Suponemos que la gobernanza de este espacio político es condición necesaria para que las organizaciones estudiantiles universitarias sean actores estratégicos en relación a las políticas sectoriales. Pero igualmente, presumimos que la efectividad política del movimiento condiciona la arena política utilizada por sus organizaciones, así como, la consistencia entre su subcultura y su estrategia.

Para responder estas preguntas la investigación integró un análisis de las dimensiones orgánicas y actorales de la Confederación. Inicialmente, se realizó un examen interpretativo de documentos primarios, que permitió identificar las transformaciones orgánicas de dicho espacio. ${ }^{7}$ Luego, se ejecutó un análisis descriptivo sobre la composición actoral, que permitió: a) identificar los cambios en el número de federaciones afiliadas y su origen corporativo (estatales - privadas) y b) reconocer las organizaciones políticas al mando de las federaciones y sus relaciones al interior de esta arena política. El supuesto operativo es que las reglas del juego y las transformaciones orgánicas, sumado al cambio en las correlaciones de fuerza, permiten establecer las condiciones efectivas de gobernanza al interior de este subsistema.

Los resultados obtenidos describen las transformaciones de la estructura orgánica y la composición actoral de la Confederación. Asimismo, se presentan las correlaciones y tendencias de las orgánicas políticas. Ambos hallazgos, permiten discutir acerca de las condiciones de funcionamiento, gobernanza y efectividad política, en especial, las restricciones y oportunidades surgidas de las interacciones internas (relaciones Mesa Ejecutiva con vocerías de zonales, federaciones y coaliciones al interior del espacio), así como, las vinculaciones con otros actores estratégicos sectoriales (stakeholders externos).

\footnotetext{
${ }^{7}$ Para este trabajo se ha analizado el siguiente corpus:

a) CONFECH (2010) Reglamento de Sala. Aprobado en la Sesión Ordinaria de 15 de agosto de 2010 realizada en la Universidad de Santiago de Chile.

Recuperado de: http://movimientoestudiantil.cl/wp-content/uploads/2015/12/2010-Reglamento-de-SalaCONFECH-1.pdf

b) CONFECH (2015) Propuesta de reglamento de Sala. Aprobada en la Sesión Ordinaria de 10 de enero de 2015, realizada en la Universidad Arturo Prat de Iquique.

c) CONFECH (2011-2015) Síntesis y Actas Sesiones, desde el 16 de abril de 2011 al 12 de septiembre de 2015 .

d) Informes de organizaciones políticas sectores centro, izquierda y ultra-izquierda 2011 a 2015.
} 
Marcelo Mella, Héctor Ríos, Ricardo Rivera, Condiciones orgánicas y correlaciones de fuerza del movimiento estudiantil chileno. Una aproximación desde la Confech (2011-2015) / Organic conditions and strength correlations of chilean student movement. An approach from Confech (2011-2015), Revista Izquierdas, 27, abril 2016, ISSN 0718-5049, pp. 124-160

\section{Marco teórico y metodología}

Nuestra perspectiva constituye un enfoque complementario de los estudios de organizaciones de jóvenes y movimientos estudiantiles desde una óptica histórica y cultural. Se reconoce la cualidad de esas miradas para esclarecer los procesos simbólicos, culturales y experienciales que dan lugar a narrativas de contestación que interpelan el sentido común y sustentan la institucionalización de la subjetividad en nuevas organizaciones sociales. ${ }^{8}$ No obstante, nos interesa esclarecer, desde una aproximación vinculada a la politología $\mathrm{y}$, en menor medida, a la sociología (politica o de las organizaciones), las condiciones formales e informales que enmarcan el modus operandi de los actores y su "juego" efectivo. "En esta dirección, se utiliza la noción de "espacio" CONFECH como lugar de competencia y disputa por la producción de capital simbólico y por el acceso a los recursos de poder. ${ }^{10}$

Autores como Huntington, ${ }^{11}$ Mainwaring y Scully, ${ }^{12}$ Peters, ${ }^{13}$ Mainwaring y Torcal, ${ }^{14}$ March y Olsen ${ }^{15}$ y Payne, ${ }^{16}$ asumen, con argumentos múltiples, que existe relación entre los niveles de institucionalización de un sistema y su estabilidad en el tiempo, debido a que, mayor nivel de institucionalización implicaría mayor acatamiento y validación de los procedimientos formales. De hecho, Mainwaring y Scully definen un sistema de partidos institucionalizado como aquel que posee reglas "razonablemente estables". ${ }^{17}$ En el mismo sentido, Mark Payne señala que la institucionalización: "contribuye a mejorar los niveles de estabilidad política así como los niveles de eficacia gubernamental; en la medida que trasforma a los mecanismos electorales y de representación parlamentaria en las principales vías de articulación de las demandas sociales; y al tiempo que facilita el acatamiento frente a las decisiones públicas."18

\footnotetext{
${ }^{8}$ Especial mención merecen los trabajos de Victor Muñoz Tamayo: Victor Muñoz. Juventud y politica en Chile. Hacia un enfoque generacional. Ultima Década No35, CIDPA, Valparaíso, Diciembre 2011, 113-141. Víctor Muñoz. Movimiento social juvenil y eje cultural. Dos contextos de reconstrucción organizativa (19761982 / 1989-2002). Ultima Década No17, CIDPA, Viña del Mar, Septiembre 2002, 41-64.

${ }^{9}$ Theodore Caplow. Dos contra uno: teoría de las coaliciones en las tríadas. Madrid, Alianza Editorial. 1974.

${ }^{10}$ Pierre Bourdieu. ¿Qué significa hablar? Economía de los intercambios lingüísticos. Madrid, AKAL, 1985. Pierre Bourdieu. Intelectuales, política y poder. Buenos Aires, EUDEBA, 1999.

${ }^{11}$ Samuel Huntington. El orden político de las sociedades en cambio, Buenos Aires, Paidós, 1992 (edición original en inglés, 1968). Véanse especialmente los capítulos 1 y 3.

12 Scott Mainwating y Timothy R. Scully. La institucionalización de los sistemas de partido en América Latina. Revista de Ciencia Política. Vol. XVII, Núm. 1-2. 1995, 63-101.

${ }_{14}^{13}$ Guy Peters. El nuevo institucionalismo. Barcelona, Gedisa. 2003.

${ }^{14}$ Scott Mainwaring y Mariano Torcal. "La institucionalización de los sistemas de partidos y la teoría del sistema partidista después de la tercera ola democratizadora". América Latina Hoy, diciembre 2005, 141-173.

${ }^{15}$ James G. March y Johan P. Olsen. The new institutionalism: Organizational factors in political life. American Political Science Review, 78, 1984, 738-749.

${ }^{16}$ Mark Payne. La política importa. Democracia y desarrollo en América Latina. Washignton D.C., BID, 2006.

${ }^{17}$ Mainwaring y Scully. op.cit., 64.

${ }^{18}$ Payne, op.cit., 167.
} 
Marcelo Mella, Héctor Ríos, Ricardo Rivera, Condiciones orgánicas y correlaciones de fuerza del movimiento estudiantil chileno. Una aproximación desde la Confech (2011-2015) / Organic conditions and strength correlations of chilean student movement. An approach from Confech (2011-2015), Revista Izquierdas, 27, abril 2016, ISSN 0718-5049, pp. 124-160

Otros autores como North, ${ }^{19}$ Helmke y Levitsky, ${ }^{20}$ sostienen que las instituciones deben ser analizadas en sus variantes "formales" e "informales". Por instituciones formales entienden normas positivas, establecidas por escrito, vale decir, "un diseño explícito de normas y estructuras". ${ }^{21} \mathrm{O}$ como dicen Freidenberg y Levistky, ${ }^{22}$ existe una organización formal: "cuando (una institución) toma decisiones de acuerdo a sus estatutos y actúa a partir de sus órganos". ${ }^{23}$ Contrario sensu, las instituciones informales pertenecen a aquella dimensión de la organización real que no corresponde a la estructura formal. De este modo, las instituciones informales surgen de derivaciones de las normas formales o provienen de prácticas fuertemente arraigadas en la cultura, y dan lugar a fenómenos tales como el personalismo, el patronazgo, el clientelismo y los conflictos de interés. ${ }^{24}$

Para efectos de este trabajo, se indagará en la relación entre reglas del juego y la composición del espacio CONFECH, bajo el supuesto que las normas contribuyen a definir resultados políticos, al menos como mecanismos de reducción de incertidumbre. En esta dirección, Adam Przeworski ha sostenido que las normas definen lo que es posible (depende estrictamente de reglas) y probable (depende de reglas y de las decisiones de los actores), más no definen a priori lo que ocurrirá efectivamente. ${ }^{25}$ Por otra parte, Rein Taagepera, refiriéndose específicamente a las reglas electorales, establece dos tipos de efectos políticos: a) efectos mecánicos (por ejemplo composición espacio y correlaciones de fuerza) y b) efectos psicológicos (por ejemplo decisiones más o menos cooperativas entre actores). ${ }^{26}$

En relación a la gobernabilidad del espacio Confederado, se analizarán los cambios en las correlaciones de fuerza, las diferentes fórmulas "monocolor" (Liderazgo de la Mesa Ejecutiva y control del Pleno por la JJCC durante 2011) y "de coalición" (Liderazgo de la Mesa Ejecutiva y control del Pleno por la alianza IA-FEL-UNE durante 2012 a 2015) para la constitución de Mesa Ejecutiva, así como los diferentes desafíos, oportunidades y restricciones que enfrentan las organizaciones para maximizar su incidencia en esta "arena política".

\footnotetext{
${ }^{19}$ Douglass North. Institutions, Institutional Change and Economic Performance. Cambridge, Cambridge University Press. 1990.

${ }^{20}$ Gretchen Helmke y Steven Levitsky. "Informal institutions and comparative politics: a research agenda". Perspectives on Politics. Vol. 2, Issue 04 / December 2004, 725-740.

${ }^{21}$ Marcelo Mella, Elementos de Ciencia Política. Conceptos, Actores y Procesos. Vol. 1, Santiago, RIL, 2012, 108.

${ }^{22}$ Flavia Freidenberg y Steven Levitsky. "Organización informal de los partidos en América Latina”. Desarrollo Económico. Vol. 46, Issue 184, 2007, 539-568.

${ }^{23}$ Ibid. 542.

${ }^{24}$ Marcelo Mella, op.cit. 2012. 240-243.

25 Adam Przeworski. Democracia y mercado. Reformas políticas y económicas en la Europa del Esta y América Latina. Cambridge, U.K.: Cambridge University Press. 1995.

${ }^{26}$ Rein Taagepera. "Electoral Systems". En Boix, C. y Stokes, S. The Oxford Handbook of Comparative Politics. Nueva York: Oxford University Press Inc. 2007.
} 
Marcelo Mella, Héctor Ríos, Ricardo Rivera, Condiciones orgánicas y correlaciones de fuerza del movimiento estudiantil chileno. Una aproximación desde la Confech (2011-2015) / Organic conditions and strength correlations of chilean student movement. An approach from Confech (2011-2015), Revista Izquierdas, 27, abril 2016, ISSN 0718-5049, pp. 124-160

Debido a las propias características del espacio político en estudio, no parece posible homologar, sin más, la noción de gobernabilidad a una "capacidad gubernamental", debido a la fragmentación del espacio Confederado y a los diseños de gobernabilidad "descentrada" que se construyen anualmente. ${ }^{27}$ En esta perspectiva, parece ajustarse a las particularidades del objeto, una noción de gobernabilidad como resultado de acuerdos entre los actores políticamente estratégicos del sistema. ${ }^{28}$ Estos acuerdos constituyen transacciones "formales" o "informales" y sus principales objetivos son: reducir la competitividad y el conflicto, controlar la agenda y modificar las relaciones de poder. ${ }^{29}$ Ciertamente, el problema de la "coordinación social" de los actores no se agota en bajar los costos de transacción internos, sino también, construir acuerdos con actores estratégicos externos al movimiento. ${ }^{30}$

En referencia al estudio de los movimientos sociales, autores que han desarrollado síntesis recientes de las perspectivas Estadounidense (Movilización de Recursos) y Europea (Identidad) concuerdan en que existe una tensión constitutiva en la trayectoria de estos actores, el clivaje entre estrategia e identidad. ${ }^{31}$

De acuerdo a Gerardo Munk, la articulación entre identidad y estrategia resulta una condición necesaria para que un movimiento social se desarrolle y no involucione. ${ }^{32}$ Para construir dicha articulación el movimiento debe asumir riesgos (controlados) y su carácter autolimitado que impide la proyección del actor hacia lo político institucional. ${ }^{33}$ Siguiendo a este autor, el proceso de desarrollo político de un movimiento social puede ser analizado conforme a dos criterios básicos: a) la arena política de operación y b) la consistencia identidad / estrategia. En la arena de operación se distingue un primer ámbito que corresponde a la sociedad civil y un segundo que corresponde a la política institucional. Se comprende que el momento original de los movimientos sociales es aquel caracterizado por consistencia entre identidad y estrategia y una operación situada en la "arena de la sociedad civil". Estos actores pueden evolucionar como un movimiento políticamente orientado mediante estrategias ofensivas que permiten su penetración en la política institucional. Pero también pueden involucionar a estadios que impiden que los movimientos, cualquiera sea

\footnotetext{
${ }^{27}$ Mark Bevir y Rod Rhodes. "A Decentred Theory of Governance: Rational Choice, Institucionalism and Interpretation". Institute of Governmental Studies, Working Paper Núm. 10, University of California, Berkeley. 2001.

${ }^{28}$ Michael Coppedge. "Instituciones y gobernabilidad democrática en América Latina”. En Antonio Camou. Los desafios de la gobernabilidad. FLACSO-IISUNAM-Plaza y Valdés. 2001.

${ }^{29}$ Leonardo Morlino. Democracia y democratizaciones. Madrid: Centro de Investigaciones Sociológicas (CIS). 2009.

${ }^{30}$ Gerardo Munck. Algunos problemas conceptuales en el estudio de los movimientos sociales. Revista Mexicana de Sociología, Vol. 57, No. 3. Jul. - Sep., 1995, 17-40. Gerardo Munck. Formação de Atores, Coordenação Social e Estratégia Política:. Problemas Conceituais hacen Estudo dos Movimentos Sociais. Revista Dados, 40 (1). 1997.

${ }^{31}$ Munck, op.cit. 1995. 17-40. Sidney Tarrow. "Power in Movement: Social Movements and Contentious Politics". Cambridge, Cambridge University Press. 2011.

${ }^{32}$ Munck, op.cit. 1995.

${ }^{33}$ Ibid. 30-32.
} 
Marcelo Mella, Héctor Ríos, Ricardo Rivera, Condiciones orgánicas y correlaciones de fuerza del movimiento estudiantil chileno. Una aproximación desde la Confech (2011-2015) / Organic conditions and strength correlations of chilean student movement. An approach from Confech (2011-2015), Revista Izquierdas, 27, abril 2016, ISSN 0718-5049, pp. 124-160

su índole, puedan contribuir a sus objetivos transformativos. Así, puede ocurrir que la estrategia predomine sobre la identidad, generándose organizaciones carentes de autonomía que Munk llama "fuerza política populista", debido a su cooptación por parte del estado o el sistema de partidos. Pero también puede ocurrir que en ciertos movimientos predomine la identidad sobre la estrategia, evolucionando a una "fuerza social fundamentalista". 34

En lo metodológico, este trabajo corresponde a un análisis descriptivo que utiliza información cualitativa y cuantitativa. Al primer tipo de información corresponde el "Reglamento de sala CONFECH", aprobado el 5 de agosto $2010^{35}$ y el documento "Propuesta de reglamento de Sala CONFECH", que fue aprobado el 10 de enero del año 2015. ${ }^{36}$ Los documentos fueron analizados usando la técnica de categorización selectiva que permite comparar unidades discursivas en base a categorías pre-definidas. ${ }^{37}$ En este caso, las categorías de análisis se basaron en la taxonomía organizacional de Mintzberg, ${ }^{38}$ sobre el proceso de decisiones y en la teoría de la movilización de recursos. ${ }^{39}$ Las categorías usadas fueron: participantes, atribuciones y funciones del proceso decisional, instancias y mecanismos de deliberación, toma de decisiones y mecanismos ejecutivos, de control y supervisión.

De la información cuantitativa, se analizan datos históricos de federaciones y organizaciones políticas que participan en el espacio del Pleno CONFECH. Para ello, hemos sistematizado una base de datos para el período 2011 a 2015 que consigna el total de federaciones afiliadas, especificando para cada caso: zonal de pertenencia, fuerza política que lidera federación respectiva, ubicación ideológica (ultraizquierda, izquierda, centro y derecha). El levantamiento de esta información se ha realizado en base a informes anuales y de coyuntura elaborado por diferentes fuerzas políticas, ${ }^{40}$ actas de sesiones CONFECH, ${ }^{41}$ revisión de prensa ${ }^{42}$ y cuatro entrevistas a informantes clave, que corresponden a expresidentes de federaciones y militantes de organizaciones políticas durante el periodo de estudio. $^{43}$

\footnotetext{
${ }^{34}$ Ibid. 32-36.

${ }^{35}$ CONFECH (2010) Reglamento de Sala. Aprobado en la Sesión Ordinaria de 15 de agosto de 2010 realizada en la Universidad de Santiago de Chile. Recuperado de: http://movimientoestudiantil.cl/wpcontent/uploads/2015/12/2010-Reglamento-de-Sala-CONFECH-1.pdf

${ }_{36}$ CONFECH (2015) Propuesta de reglamento de Sala. Aprobada en la Sesión Ordinaria de 10 de enero de 2015, realizada en la Universidad Arturo Prat de Iquique.

${ }^{37}$ Uwe Flick. Introducción a la investigación cualitativa. Madrid, Morata, 2004.

${ }^{38}$ Henry Mintzberg. La estructuración de las organizaciones. Barcelona, Ariel, 1984.

39 John D. McCarthy and Mayer N. Zald. "Resource Mobilization and Social Movements: A Partial Theory". American Journal of Sociology. 82.6, 1977, 1212-1241.

${ }^{40}$ Informes de organizaciones políticas sectores centro, izquierda y ultra-izquierda 2011 a 2015.

${ }^{41}$ CONFECH (2011-2015) Síntesis y Actas Sesiones, desde el 16 de abril de 2011 al 12 de septiembre de 2015.

${ }^{42}$ Para el período 2011-2015, se ha realizado una revisión de la prensa hasta el mes de septiembre de cada año, considerando que la movilización estudiantil, para esta fecha, se encuentra usualmente finalizada. Los periódicos consultados fueron: La Tercera, El Mostrador y The Clinic.

${ }^{43}$ El detalle de entrevistas utilizadas en este artículo es el siguiente:
} 
Marcelo Mella, Héctor Ríos, Ricardo Rivera, Condiciones orgánicas y correlaciones de fuerza del movimiento estudiantil chileno. Una aproximación desde la Confech (2011-2015) / Organic conditions and strength correlations of chilean student movement. An approach from Confech (2011-2015), Revista Izquierdas, 27, abril 2016, ISSN 0718-5049, pp. 124-160

Suponemos que el espacio de la multifederativa, al tratarse de un sistema "a escala", puede ser analizado utilizando categorías, dimensiones y problemáticas elaboradas por la ciencia política en el estudio de los sistemas de partidos, tales como: dinámicas de institucionalización (considerando avances y retrocesos), gobernanza y gestión política referida a órganos con capacidad ejecutiva (considerando estrategias de reducción de costos para toma de decisiones), así como modos de aprendizaje político en organizaciones y subculturas políticas, entre otros diversos aspectos.

\section{Condiciones constituyentes}

Aunque la Federación de Estudiantes de la Universidad de Chile (FECH) fue creada en 1907, el origen histórico del movimiento estudiantil chileno, convencionalmente, se ubica en la década de 1920 y 1930. La característica principal del movimiento estudiantil durante estos primeros años, es su carácter autónomo respecto del sistema de partidos de la época, como respuesta a la oligarquización de la política institucional en las décadas iniciales del siglo XX y, después de 1925, como espacio de resistencia frente a la restauración del hiperpresidencialismo.

El primer impulso estuvo dado por una fuerte orientación anarquista, rebelde y libertaria, puesta al servicio de la transformación general de la sociedad chilena. ${ }^{44}$ Para este objetivo, el movimiento se expandió en base a una narrativa idealista, autolimitada y a la generación de pensamiento ideológico desde órganos como el Centro de Estudios Sociales Francisco Ferrer y el Periódico "Claridad" (Fundado en 1920). Entre los primeros referentes estudiantiles anarquistas constituidos en la Universidad de Chile desde 1922 se cuentan "Lux" en Medicina, "Renovación" en Derecho, "Insurrección" en Comercio, "Rebelión" en Instrucción Secundaria y "Spartaco" en Bellas Artes. ${ }^{45}$ Del mismo modo, surgen durante este período, líderes destacados como el vicepresidente de la FECH Juan Gandulfo, Oscar Schnacke y Eugenio González Rojas, éstos dos últimos, fundadores del Partido Socialista de Chile en 1933.

La transición hacia un movimiento estudiantil que desarrolló una estrategia ofensiva y de penetración en lo político institucional, se produjo en los inicios de la década de 1930. La

a) Mella M. Ríos H. y Rivera R. Entrevista a militante organización política perteneciente al sector ultraizquierda. Santiago, Septiembre 2015.

b) Mella M. Ríos H. y Rivera R. Entrevista a presidente federación estudiantes perteneciente al sector ultraizquierda. Santiago, Agosto 2015.

c) Mella M. Ríos H. y Rivera R. Entrevista a militante organización política perteneciente al sector izquierda. Santiago, Noviemre 2015.

d) Mella M. Ríos H. y Rivera R. Entrevista a militante organización politica perteneciente al sector centro. Santiago, Noviembre 2014.

${ }^{44}$ Manuel Garretón. El movimiento estudiantil: conceptos e historia. Biblioteca del Movimiento Estudiantil. Tomo IV. Santiago de Chile. Ediciones SUR. 1984, 69.

${ }^{45}$ Ibid. 73. 
Marcelo Mella, Héctor Ríos, Ricardo Rivera, Condiciones orgánicas y correlaciones de fuerza del movimiento estudiantil chileno. Una aproximación desde la Confech (2011-2015) / Organic conditions and strength correlations of chilean student movement. An approach from Confech (2011-2015), Revista Izquierdas, 27, abril 2016, ISSN 0718-5049, pp. 124-160

doctrina de la prescindencia partidaria y el carácter antibolchevique del movimiento en los años 20, fueron sustituidas por la penetración del marxismo y la bolchevización de las organizaciones estudiantiles como resultado de la crisis económica de 1929 y la experiencia de los gobiernos de Alessandri e Ibáñez que significaron una regresión desde el punto de vista de la concentración del poder en el ejecutivo.

En esta dirección, los partidos Comunista, Socialista, Radical y el Socialcristianismo empezaron a influir, controlar y dirigir a través de juventudes políticas a crecientes sectores del movimiento estudiantil desde la década de 1930. Como ejemplo de estos referentes se cuenta el Grupo Avance grupo político con actuación en la reorganización de la FECH disuelta en 1926 durante la dictadura de Ibáñez. En este grupo se reunieron jóvenes comunistas y socialistas como Oscar Waiss, Salvador Allende, Tomás Chadwick, Volodia Teitelboim, entre otros. Por su parte, los grupos socialcristianos constituyeron el Grupo Renovación, con estudiantes e intelectuales como: Eduardo Frei, Manuel Antonio Garretón, Radomiro Tomic, Rafael A. Gumucio y Bernardo Leighton.

Estos dos momentos constitutivos del movimiento estudiantil delinea a grandes rasgos las alternativas dicotómicas del dilema entre identidad y estrategia planteado por Gerardo Munk. Un primer momento donde el movimiento actúa situado en la sociedad civil, con predominio de la identidad sobre la estrategia y rechazan la idea de constituir partidos, por tanto, se caracterizan por un fuerte carácter auto-limitado y tendencias fundamentalistas. La segunda alternativa, corresponde al proceso generado desde 1930 en que el movimiento estudiantil se proyectó al espacio de la política institucional con el consiguiente riesgo de pérdida de su autonomía. La historia del movimiento estudiantil hasta 1973, desde el punto de vista del dilema identidad y estrategia, transita por diversas combinaciones entre estas alternativas dicotómicas. Por su parte, el papel del movimiento estudiantil durante el período autoritario de Pinochet, dada su extraordinaria relevancia y complejidad, escapa a los objetivos de este artículo que analiza el funcionamiento del espacio de la política estudiantil en contexto de estabilidad institucional.

Cuadro $\mathrm{N}^{\circ}$ 1. Coyunturas del movimiento estudiantil desde 1990
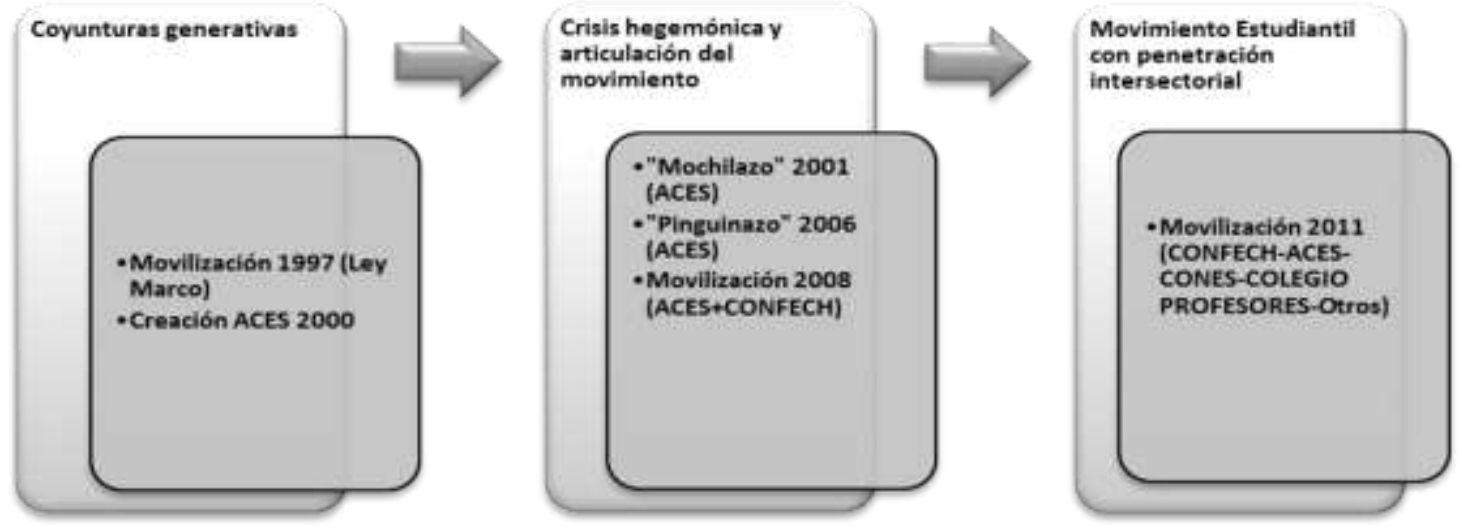

Fuente: Elaboración propia en base a Muñoz (2009), Thielemann (2011), Agacino (2013), Avendaño (2014). 
Marcelo Mella, Héctor Ríos, Ricardo Rivera, Condiciones orgánicas y correlaciones de fuerza del movimiento estudiantil chileno. Una aproximación desde la Confech (2011-2015) / Organic conditions and strength correlations of chilean student movement. An approach from Confech (2011-2015), Revista Izquierdas, 27, abril 2016, ISSN 0718-5049, pp. 124-160

La historia del movimiento estudiantil chileno después de Pinochet se caracterizó al menos por tres momentos que representan estadios de desarrollo de la acción colectiva sectorial (Cuadro $\mathrm{N}^{\circ}$ 1): a) coyuntura generativa, b) crisis hegemónica y articulación del movimiento y c) proyección política y penetración intersectorial. ${ }^{46}$

a) Coyuntura generativa: durante este momento se produce la movilización por la Ley Marco para la Educación Superior el año 1997 y la creación de la Asamblea Coordinadora de Estudiantes Secundarios (ACES) en el 2000.

A nivel de sistema político el período se encuentra marcado por un conjunto de rupturas en las tendencias y condiciones que caracterizaron la llegada al poder de la Concertación en 1990. Una ruptura fundamental consistió en los efectos en Chile de la crisis económica internacional de 1997 (Crisis Asiática) que producen la detención y una caída abrupta en el crecimiento tendencial del PIB, así como diversas medidas correctivas por parte del gobierno de Frei Ruiz Tagle. Otro fenómeno relevante radicó en el "factor electoral" que se manifiesta con las elecciones parlamentarias de 1997, momento en el que por primera vez después de recuperada la democracia aparece, con la acumulación de votos nulos $(13,54 \%)$, blancos $(4,7 \%)$ y abstención (13,7\%), una brecha evidente entre los intereses de la clase política y los electores (total de nulos, blancos y abstención $31,61 \%$, en contexto de voto obligatorio). ${ }^{47}$ De alguna manera, el debate entre "autocomplacientes" y "autoflagelantes" producido en la Concertación por estos años, responde precisamente a la constatación de esta pérdida de anclaje social, generando fuerzas centrífugas crecientes en la historia posterior de esta Coalición.

b) Crisis hegemónica y articulación del movimiento: durante esta fase se produce la movilización de secundarios del año 2001, conocida como "El Mochilazo", organizada por la ACES y que adquiere una alta convocatoria en la Región Metropolitana de Santiago y los Colegios Emblemáticos. ${ }^{48}$ Del mismo modo, durante el año 2006 se produce la segunda gran movilización estudiantil de esta fase, organizada por ACES, conocida como el movimiento de los "Pinguinos", que a diferencia del año 2001, consigue una alta y

\footnotetext{
${ }^{46}$ Para profundizar acerca de estas coyunturas, véase: Victor Muñoz. Generaciones en tránsito: Juventud universitaria e izquierdas políticas en Chile y México (Universidad de Chile- UNAM 1984-2006). (Tesis doctoral). Universidad Nacional Autónoma de México. México. 2008. Luis Thielemann. "Para una periodificación del Movimiento Estudiantil de la transición (1987-2011)". En Sistematización de Talleres para la Acción Estudiantil. CEFECH-Heinrich-Böll-Stiftung. Santiago, 2011. Octavio Avendaño. "Fracturas y representación política en el movimiento estudiantil: Chile 2011". Última década, 22(41), 2014, 41-68. Ricardo Rivera. Los Pilares Fundamentales del Movimiento Estudiantil en Chile: 2000-2014 (Tesis de pregrado para optar al Título de Periodista). Escuela de Periodismo. Universidad de Santiago de Chile. Santiago. 2015.

${ }^{47}$ Peter Siavelis. "Continuidad y transformación del sistema de partidos en una transición modelo". En: El modelo chileno. Democracia y desarrollo en los noventa, Santiago, LOM, 1999, 251.

${ }^{48}$ Rafael Agacino. "Movilizaciones estudiantiles en Chile. Anticipando el futuro". Educação em Revista, Marília, Vol. 14, n. 1, p. 7-20, Jan.-Jun., 2013.
} 
Marcelo Mella, Héctor Ríos, Ricardo Rivera, Condiciones orgánicas y correlaciones de fuerza del movimiento estudiantil chileno. Una aproximación desde la Confech (2011-2015) / Organic conditions and strength correlations of chilean student movement. An approach from Confech (2011-2015), Revista Izquierdas, 27, abril 2016, ISSN 0718-5049, pp. 124-160

prolongada convocatoria a nivel nacional. Finalmente, durante el 2008, se produce un nuevo proceso de movilización nacional que tiene la importancia de constituir el esfuerzo más importante de convergencia entre estudiantes secundarios (Reunidos en ACES) y universitarios (Reunidos en $\mathrm{CONFECH}$ ) desde el regreso a la democracia.

En lo político esta fase aparece marcada por dos gobiernos del sector "progresista" de la Concertación (Ricardo Lagos, de militancia PPD que gobierna durante el período 2000 a 2005 y Michelle Bachelet, de militancia PS que gobierna durante el período 2006 a 2010). Tanto durante la presidencia de Lagos como de Bachelet, se observan rasgos que evidencian la crisis de hegemonía para el proyecto concertacionista. Por una parte, en ambos gobiernos la elección presidencial se dirime en segunda vuelta, siendo el triunfo de Lagos el más dramático con una escasa ventaja sobre el candidato de la derecha Joaquín Lavín. (51,31\% frente a 48,69\%, equivalente a 187.589 votos) Por otra parte, ambos gobiernos tienen una base de respaldo a nivel parlamentario menor que los dos gobiernos democristianos precedentes. Si Aylwin y Frei Ruiz Tagle constituyeron gobierno sobre la base de que su partido era el pivote de la coalición con un nivel de control nunca menor al $30 \%$ de los escaños en la Cámara Baja, Lagos y Bachelet contaron con un control a nivel de Diputados que oscilo entre $16 \%$ y $12 \%$ respectivamente. Además del desempeño electoral de los partidos de la Concertación, en estos años se manifestó con intensidad la ausencia de un proyecto histórico y capital ideológico propio para los partidos de la izquierda "renovada"; acumulándose hechos que mostraban las distancias entre el socialismo pre y post autoritario. Entonces, el paso de gobiernos DC a gobiernos de liderazgos progresistas en la concertación no representó mucho más que cambios en los estilos y "modales" de gestión. A nivel político institucional, se observa enervamiento y debilidad de la capacidad regulatoria del estado frente a grandes intereses corporativos (control de la corrupción, conflictos de intereses entre regulador y regulados, fiscalización y aplicación de sanciones en incumplimiento de obligaciones en proyectos de alto impacto ambiental), orientación de políticas de profundización del modelo de mercado (políticas educacionales) y tendencia a prolongar, sino reproducir la institucionalidad y prácticas autoritarias (gestión política del conflicto en la Araucanía y persecución de líderes de la Coordinadora Arauco Malleco).

c) Proyección política y penetración intersectorial: durante esta etapa se desarrolla la movilización del año 2011, proceso en el que converge el movimiento universitario conducido por la Confederación, los secundarios concentrados en ACES y CONES, el Colegio de Profesores y otros actores ciudadanos multisectoriales. ${ }^{49}$ Luego de esta coyuntura, el movimiento estudiantil se convierte en un activador de movilizaciones multisectoriales que demandan desde diferentes intereses la superación de políticas e instituciones que reproducen el modelo de dominación de mercado.

Junto con el surgimiento de una poderosa "coalición callejera" constituida para erosionar la legitimidad del régimen político y construir un quiebre con la institucionalidad surgida en

${ }^{49}$ Mayol y Azocar, op.cit., 2011. Garcés, op.cit., 2011. Salazar, op.cit., 2012. 
Marcelo Mella, Héctor Ríos, Ricardo Rivera, Condiciones orgánicas y correlaciones de fuerza del movimiento estudiantil chileno. Una aproximación desde la Confech (2011-2015) / Organic conditions and strength correlations of chilean student movement. An approach from Confech (2011-2015), Revista Izquierdas, 27, abril 2016, ISSN 0718-5049, pp. 124-160

dictadura, durante el año 2010, se produjo la pérdida del poder por parte de la Concertación, y la llegada de la derecha a La Moneda por vía electoral luego de 52 años (desde la victoria de Jorge Alessandri en 1958). El gobierno de Sebastián Piñera compartió con Lagos y Bachelet su condición de presidentes minoritarios, elegido en segunda vuelta y con un partido pivote de coalición que alcanzó un $17.8 \%$ de escaños en la Cámara Baja, reproduciendo las restricciones de sus dos predecesores en la relación con el legislativo. Aunque el terremoto de 2010 pareció inicialmente extender la "luna de miel" del gobierno con niveles de aprobación en la opinión pública cercanos al 45\% durante el primer año, la escasa experiencia de sus equipos en la administración pública, los reiterados errores comunicacionales del gobierno y del propio presidente, la débil disciplina de la coalición de gobierno, el débil anclaje en organizaciones sociales de los partidos de derecha y la reactivación de la coalición callejera surgida desde las movilizaciones estudiantiles, gatillaron el desplome de Piñera durante el primer semestre de 2011. De tal forma, desde diciembre de 2010 a junio de 2011 el gobierno de Piñera cae desde el 44\% al 27\%, equivalente a 17 puntos porcentuales en seis meses. La conducción de la movilización estudiantil del año 2011, estuvo a cargo de las Juventudes Comunistas, que desde 1990 hasta esa fecha, había sido el principal excluido por la Concertación.

\section{Condiciones orgánicas}

La Confederación de Estudiantes de Chile constituye el principal órgano de articulación y coordinación política de los estudiantes universitarios durante la democracia postautoritaria. Constituida en 1984, en el contexto de las jornadas de protesta nacional para derrocar la dictadura, esta organización se creó con un total de 20 organizaciones estudiantiles, provenientes de universidades estatales y privadas tradicionales.

Pese a la larga trayectoria como organización, no ha desarrollado en el periodo 1984 - 2015 una definición de estatutos y estructura orgánica formal que permita equilibrar el componente "identitario" y el componente "estratégico" del movimiento. ${ }^{50}$ En efecto, desde el retorno a la democracia es posible identificar al menos tres convocatorias a congresos que tuvieron como finalidad definir estatutos y formalizar la organización. La primera convocatoria fue realizada en 1998, en el marco del conflicto por las políticas de financiamiento para el acceso de la educación superior. La segunda en el 2003, en el marco de la activación del movimiento de estudiantes secundarios. La tercera convocatoria en el 2012, año posterior a las masivas movilizaciones estudiantiles del 2011. A pesar del objetivo común que convocó a los tres congresos, ninguno alcanzó el propósito de formalizar el funcionamiento de la organización, existiendo hasta esa fecha solo normativas que regulaban el funcionamiento del Pleno y algunas atribuciones de sus miembros. En este contexto se elaboran los "Reglamento de sala CONFECH" de 2010 y la "Propuesta de reglamento de sala CONFECH” de 2015.

\footnotetext{
${ }^{50}$ Munk, op.cit. 1995.
} 
Marcelo Mella, Héctor Ríos, Ricardo Rivera, Condiciones orgánicas y correlaciones de fuerza del movimiento estudiantil chileno. Una aproximación desde la Confech (2011-2015) / Organic conditions and strength correlations of chilean student movement. An approach from Confech (2011-2015), Revista Izquierdas, 27, abril 2016, ISSN 0718-5049, pp. 124-160

\section{Funcionamiento del espacio político}

La CONFECH es una agrupación paritaria de federaciones de estudiantes universitarios que actúan colectivamente, manteniendo cada uno de los entes afiliados su soberanía y autonomía. Considerando su carácter escencial, actúa como órgano coordinador y sistema de alianzas entre federaciones estudiantiles que se reconocen como pares y promueven ciertos intereses comunes.

En términos orgánicos, se compone de cinco niveles decisionales (Cuadro $\mathrm{N}^{\circ} 2$ ). Las "Federaciones", que corresponden a la unidad base. El "Pleno", instancia en la que se reúnen todas las federaciones en igual condición de atribuciones y deberes. Los "Zonales", correspondientes a espacios de coordinación entre federaciones que comparten un espacio territorial común. Las "Vocerías Zonales", que corresponden a los representantes elegidos mediante diversos mecanismos por las federaciones miembros de un zonal. La "Mesa Ejecutiva" ${ }^{\natural 1}$, que constituye la instancia máxima de representación, compuesta por los voceros de cada Zonal, que actúan como voceros nacionales. Además de estas instancias existe la "Mesa Federativa" 52 , responsable de convocar y moderar los plenos y sesiones regulares o extraordinarias, a partir de los acuerdos de plenos anteriores.

\section{Cuadro N². Organigrama Confederación de Estudiantes de Chile 2011-15}

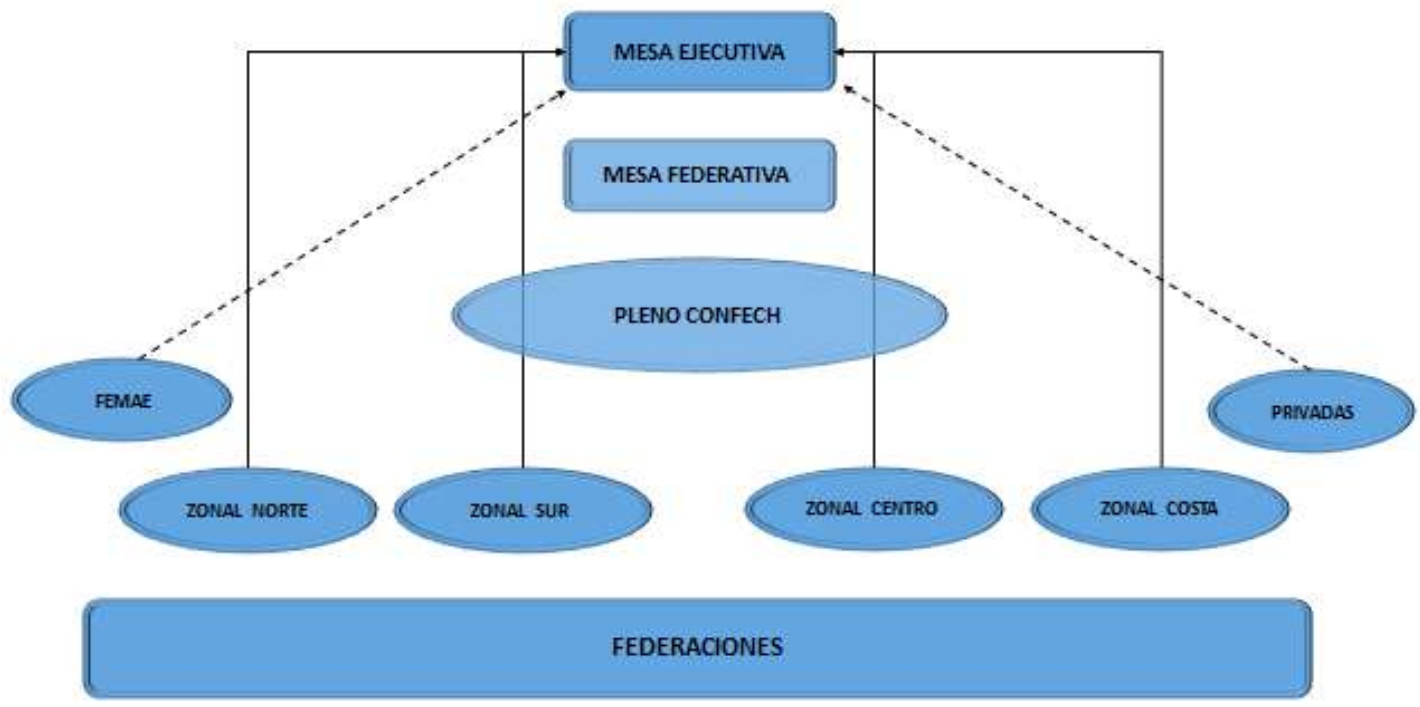

Fuente: Elaboración propia en base a reglamento de sala, documentos y entrevistas a informantes claves.

\footnotetext{
${ }^{51}$ La "Mesa Ejecutiva" está compuesta por los voceros de cada zonal y tiene como principal misión comunicar e implementar los acuerdos emanados del Pleno. Sus principales funciones son comunicar las posiciones de la organización a la opinión pública, representar sus intereses en otras instancias de participación, coordinar recursos y acciones que permitan implementar las decisiones definidas por el Pleno.

${ }^{52}$ La "Mesa Federativa" opera como agente moderador, responsable de organizar y guiar el Pleno. Sus funciones son facilitar las condiciones de desarrollo del Pleno, guiar la sesión, conducir y contabilizar votaciones, realizar actas y comunicarlas a las federaciones.
} 
Marcelo Mella, Héctor Ríos, Ricardo Rivera, Condiciones orgánicas y correlaciones de fuerza del movimiento estudiantil chileno. Una aproximación desde la Confech (2011-2015) / Organic conditions and strength correlations of chilean student movement. An approach from Confech (2011-2015), Revista Izquierdas, 27, abril 2016, ISSN 0718-5049, pp. 124-160

En términos espaciales o territoriales, la Confederación consta de dos dimensiones. Una basal o local, que corresponde al posicionamiento particular de las universidades y sus respectivas federaciones, entendidas como entidades con mecanismos y sistemas propios de funcionamiento. Otro plano es el central que reúne al conjunto de federaciones afiliadas y sus representantes, correspondiente al Pleno CONFECH, espacio que constituye el escenario de discusión, toma de acuerdos y generación de posiciones colectivas a nivel nacional.

Sobre el modus operandi, el Pleno funciona mediante sesiones regulares y extraordinarias. Las regulares se realizan quincenalmente. Las extraordinarias se realizan en situaciones particulares y requieren de acuerdos y convocatoria de un número determinado de federaciones, según normativa vigente.

Asimismo, existe una estructura de coordinación complementaria conocida como "Zonales". Conforme a los reglamentos analizados, los Zonales corresponden a instancias de organización territorial o espacios paralelos al Pleno de federaciones. Cada Zonal tiene la potestad de definir sus propias normas y mecanismos de coordinación. Su principal, atribución es elegir a los voceros que conforman la Mesa Ejecutiva y definir los lineamientos de acción de sus respectivos voceros. Durante el 2011 y bajo la presión por incluir expresiones disidentes del movimiento estudiantil se produjo la reestructuración de la Mesa Ejecutiva y la incorporación de voceros provenientes de las Universidades Privadas no tradicionales y la Federación Mapuche de Estudiantes (FEMAE). En ambos casos, se trataba de abrir espacios frente a grupos de presión (Ues Privadas y FEMAE) que pudieran afectar la unidad del movimiento a nivel nacional o, en su defecto, fortalecer la gobernabilidad del espacio. ${ }^{53} \mathrm{El}$ ingreso de estos grupos de presión a la Mesa Ejecutiva constituyó una muestra de las prácticas informales que subyacen y se reproducen en el funcionamiento de la Confederación, así como también una evidencia fehaciente de la superación de su incipiente institucionalidad.

En base a esta descripción, se representa al espacio de la Confederación como una orgánica de tipo horizontal, desprovista de especialización funcional, de mecanismos de coordinación y una estructura orgánica desarrollada. Corresponde a una organización de tipo política, según la tipología de Mintzberg, ${ }^{54}$ caracterizada por una permanente tendencia a la dispersión y cuyo funcionamiento depende de correlaciones ocasionales e inestables

\footnotetext{
${ }^{53}$ Efectivamente, entre el segundo semestre de 2011 y el primero de 2012 se produjo la reestructuración de la Mesa Ejecutiva cuyos fundamentos iniciales fueron; mantener el volumen de la movilización y evitar la fragmentación y radicalización del espacio. A este respecto, véase: La Tercera (09-01-2012). Confech fija condiciones para admitir federaciones de Ues. privadas al Pleno. http://www.latercera.com/noticia/nacional/2012/01/680-423108-9-confech-fija-condiciones-para-admitirfederaciones-de-ues-privadas-al-pleno.shtml. The Clinic (15-04-2012). Confech reorganiza su estructura y fija primera marcha del año para el 25 de abril. http://www.theclinic.cl/2012/04/15/confech-reorganiza-suestructura-y-fija-primera-marcha-del-ano-para-el-25-de-abril/

${ }^{54}$ Mintzberg, op.cit. 1984.
} 
Marcelo Mella, Héctor Ríos, Ricardo Rivera, Condiciones orgánicas y correlaciones de fuerza del movimiento estudiantil chileno. Una aproximación desde la Confech (2011-2015) / Organic conditions and strength correlations of chilean student movement. An approach from Confech (2011-2015), Revista Izquierdas, 27, abril 2016, ISSN 0718-5049, pp. 124-160

entre actores en transformación. Este tipo de organización, al carecer de mecanismos de coordinación y estructuras estables, se encuentra determinada en su evolución por la composición política del espacio y sus tendencias internas. ${ }^{55}$

\section{Reglas del juego}

Las modificaciones normativas acaecidas en los años 2011 y 2015, muestran que a nivel del Pleno de la multifederativa, aumentó la capacidad de control sobre los representantes e instancias ejecutivas, formalizando $\mathrm{y}$ fortaleciendo los mecanismos para levantar acusaciones de incumplimiento de deber y falta de probidad. Dado el aumento del número de federaciones afiliadas, se flexibiliza el quórum para sesionar, que pasa de un número fijo a una proporción. (15 a 1/3) Asimismo, se formalizan y articulan nuevas estructuras orgánicas al interior del espacio. Se crean Zonales y vocerías nacionales, se formalizan atribuciones y funciones de la Mesa Ejecutiva.

Algunos de estos cambios fueron progresivos y se fijaron tardíamente en el documento de 2015, el que constituye una síntesis de prácticas habituales que fueron mantenidas de manera informal, durante los últimos años, para afrontar las diferentes coyunturas. En consideración con los cambios descritos, se identifican tendencias orgánicas, ligadas al complejo proceso de institucionalización y establecimiento de rutinas formales.

- $\quad$ Primero, se observa una tendencia al fortalecimiento de la capacidad ejecutiva de la organización que mejora la coordinación entre las federaciones afiliadas, optimiza la estrategia comunicacional y canaliza la comunicación con sus contrapartes externas (Gobierno, MINEDUC, Congreso, entre otros).

- Segundo, se aprecia un aumento de los mecanismos de control a los órganos ejecutivos. Esto implica que se fortalecen la supervisión de los representantes por las bases, con el fin de resguardar la representatividad y legitimidad de la Mesa Ejecutiva.

- $\quad$ Tercero, se visualiza una mayor articulación entre el Pleno y la Mesa Ejecutiva por el fortalecimiento de estructuras de intermediación (Zonales). Estas estructuras, si bien no tienen atribuciones decisionales, constituyen mecanismos de coordinación local que facilitan la interacción y consolidan el carácter nacional de la Confederación.

Estos cambios, si bien representan una complejidad orgánica creciente, no constituyen un cambio de la estructura; sino más bien, ajustes funcionales y adaptativos de la organización al ambiente. En este sentido, es posible constatar una sincronía entre la coyuntura del 2011, donde la CONFECH lideró el Movimiento Nacional por la Educación, y sus proceso de cambios orgánicos.

\footnotetext{
${ }^{55}$ McCarthy \& Zald, op.cit.1977. Mintzberg, op.cit, 1984.
} 
Marcelo Mella, Héctor Ríos, Ricardo Rivera, Condiciones orgánicas y correlaciones de fuerza del movimiento estudiantil chileno. Una aproximación desde la Confech (2011-2015) / Organic conditions and strength correlations of chilean student movement. An approach from Confech (2011-2015), Revista Izquierdas, 27, abril 2016, ISSN 0718-5049, pp. 124-160

La masividad de las movilizaciones, el carácter nacional del conflicto y el constante enfrentamiento con el Estado, constituyeron factores de desarrollo de las capacidades ejecutivas y de sus instancias de coordinación. Este proceso se manifestó en la formalización de funciones de la Mesa Ejecutiva, en el aumento de miembros y en la creación de los Zonales como mecanismos de coordinación territorial. A pesar de dicho fortalecimiento, aumentaron las tensiones entre los actores políticos internos, que se expresaron como críticas a la Mesa Ejecutiva desde Zonales y otras federaciones. Para atenuar esta tensión, se multiplicaron los mecanismos de control de base, para regular la concentración de poder en la Mesa Ejecutiva y robustecer el accountability vertical de la organización.

Tabla N¹. Cambios orgánicos CONFECH 2011 - 2015.

\begin{tabular}{|c|c|c|}
\hline & \multicolumn{2}{|c|}{ ATRIBUCIONES } \\
\hline ESTRUCTURAS & 2011 & 2015 \\
\hline \multirow[t]{6}{*}{ FEDERACIONES } & Participan del Pleno & Participan del Pleno \\
\hline & Votan & Votan \\
\hline & Censuran a voceros & Destituyen a voceros (Incumplimiento \\
\hline & (Contravenir acuerdos, & y abandono de deberes, faltas a la \\
\hline & $\begin{array}{l}\text { actuar autónomamente, } \\
\text { abandono de deberes) }\end{array}$ & $\begin{array}{l}\text { probidad, negligencia de funciones, } \\
\text { contravenir acuerdos). }\end{array}$ \\
\hline & Requiere $2 / 3$ del Pleno & Requiere $4 / 7$ del Pleno. \\
\hline PLENO & $\begin{array}{l}\text { Quórum de } 15 \text { para } \\
\text { sesionar. }\end{array}$ & Quórum de 1/3 (16) para sesionar \\
\hline & Convoca al Pleno & Convoca al pleno \\
\hline \multirow{6}{*}{ FEDERATIVA } & Redacta Acta del Pleno & Define Tabla (en base a agenda y \\
\hline & Modera en Pleno (asigna & propuestas de cada Federación) \\
\hline & palabra, regula Tabla y & Redacta Acta del Pleno \\
\hline & organiza votaciones) & Modera el Pleno (asigna palabra, regula \\
\hline & & Tabla y organiza votaciones) \\
\hline & & Redacta y socializa Acta del Pleno \\
\hline \multirow[t]{4}{*}{ ZONALES } & No especifica & Coordina territorialmente Federaciones \\
\hline & & $\begin{array}{lll}\text { (Zonales } & \text { son } & \text { territorialmente } \\
\text { autónomas) } & & \end{array}$ \\
\hline & & Aplica políticas CONFECH \\
\hline & & Define estatutos propios. \\
\hline $\begin{array}{l}\text { VOCERIAS } \\
\text { NACIONALES }\end{array}$ & No especifica & $\begin{array}{l}\text { Representa a CONFECH frente a } \\
\text { autoridades y medios de comunicación. } \\
\text { Coordina actividades y movilizaciones. } \\
\text { Implementa política de CONFECH }\end{array}$ \\
\hline \multirow{4}{*}{$\begin{array}{c}\text { MESA } \\
\text { EJECUTIVA }\end{array}$} & No especifica & Dirige la CONFECH \\
\hline & & Ejecuta la voluntad de la \\
\hline & & Confederación \\
\hline & & $\begin{array}{l}\text { Vela por cumplimiento de objetivos } \\
\text { planteados en las plenarias. }\end{array}$ \\
\hline
\end{tabular}


Marcelo Mella, Héctor Ríos, Ricardo Rivera, Condiciones orgánicas y correlaciones de fuerza del movimiento estudiantil chileno. Una aproximación desde la Confech (2011-2015) / Organic conditions and strength correlations of chilean student movement. An approach from Confech (2011-2015), Revista Izquierdas, 27, abril 2016, ISSN 0718-5049, pp. 124-160

Fuente: Elaboración propia en base a Reglamento de Sala CONFECH (2010) y Propuesta de reglamento de Sala CONFECH (2015).

\section{Cambios en la composición del espacio}

En términos generales, la CONFECH 2015 estuvo compuesta por 54 federaciones de estudiantes. ${ }^{56}$ Este valor fluctúa de un año a otro, dada la desarticulación de algunas federaciones, la unificación de otras y la no participación o desvinculación de federaciones que deciden no asistir a los plenos. Pese a estas fluctuaciones, durante el periodo 2011-2015 se observan dos características en la membresía de federaciones (Ver tabla $\mathrm{N}^{\circ}$ 2). Primero, se advierte un aumento significativo del número de federaciones afiliadas, posterior al año 2011 (41 a 54). Segundo, se percibe una diversificación del tipo de federaciones que se han afiliado, por la inclusión masiva de organizaciones provenientes del sector privado no tradicional.

Tabla $\mathrm{N}^{\circ}$ 2. Membresía de federaciones por tipo de Universidad

\begin{tabular}{|c|c|c|c|c|c|c|c|}
\hline & \multicolumn{5}{|c|}{ Tipo Universidad } & \\
\hline Año & \multicolumn{2}{|c|}{ Estatal } & \multicolumn{2}{|c|}{ Priv. no Tradicional } & \multicolumn{2}{|c|}{ Priv. Tradicional } & Total \\
\hline $\mathbf{2 0 1 1}$ & 23 & $56,1 \%$ & 2 & $4,9 \%$ & 16 & $39,0 \%$ & 41 \\
\hline $\mathbf{2 0 1 2}$ & 23 & $46,0 \%$ & 11 & $22,0 \%$ & 16 & $32,0 \%$ & 50 \\
\hline $\mathbf{2 0 1 3}$ & 23 & $45,1 \%$ & 12 & $23,5 \%$ & 16 & $31,4 \%$ & 51 \\
\hline $\mathbf{2 0 1 4}$ & 23 & $42,6 \%$ & 15 & $27,8 \%$ & 16 & $29,6 \%$ & 54 \\
\hline $\mathbf{2 0 1 5}$ & 23 & $42,6 \%$ & 15 & $27,8 \%$ & 16 & $29,6 \%$ & 54 \\
\hline
\end{tabular}

Fuente: Elaboración en base a informes de fuerzas políticas y actas $\mathrm{CONFECH}$

Como se aprecia en la tabla $\mathrm{N}^{\circ} 2$, la CONFECH durante el 2011 se componía por 41 federaciones. De estas, 23 correspondían al sector estatal y 16 a universidades privadas tradicionales, existiendo una participación del sector estatal equivalente al $56,1 \%$ y una del sector tradicional privado de 39,0\%. En el 2012 esta composición se ve trastocada, dado que se aprueba el ingreso y participación de federaciones de universidades privadas no tradicionales. La revisión de la documentación indica que entre el periodo 2012-2014 se produjo una incorporación relevante de federaciones de universidades privadas (ingresan 13 federaciones en 4 años). ${ }^{57}$ Algunas de estas nuevas federaciones afiliadas no poseían mayor tradición de organización y se articularon durante las movilizaciones del 2011, como la Federación de Estudiantes de la Universidad Bernardo O’Higgins, la Federación de la Universidad Santo Tomás y la Federación de la Universidad Diego Portales.

\footnotetext{
${ }^{56}$ Evaluación realizada hasta marzo del 2015. Se constará según actas CONFECH que con posterioridad a marzo 2015 se integran ocho nuevas federaciones, las cuales no han sido consideradas en este estudio.

${ }^{57}$ CONFECH (2011-2015) Síntesis y Actas Sesiones, desde el 16 de abril de 2011 al 12 de septiembre de 2015.
} 
Marcelo Mella, Héctor Ríos, Ricardo Rivera, Condiciones orgánicas y correlaciones de fuerza del movimiento estudiantil chileno. Una aproximación desde la Confech (2011-2015) / Organic conditions and strength correlations of chilean student movement. An approach from Confech (2011-2015), Revista Izquierdas, 27, abril 2016, ISSN 0718-5049, pp. 124-160

Grafico $\mathrm{N}^{\circ}$ 1. Federaciones por año según membresía (En porcentajes sobre total anual)

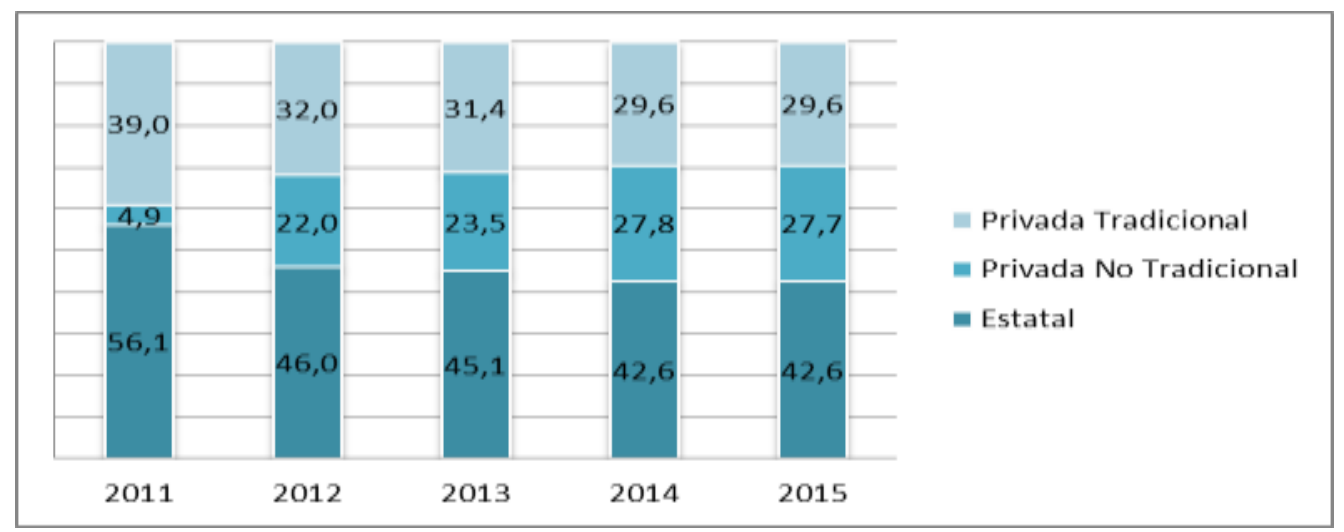

Fuente: Elaboración en base a informes de fuerzas políticas y actas CONFECH

Durante el 2015 aumentó significativamente el número total de federaciones afiliadas, que alcanzó a 54 federaciones, el número más alto en la historia de la multifederativa como organización. De estas, $23(42,6 \%)$ provienen de universidades estatales, $16(29,6 \%)$ de universidades privadas tradicionales, $15(27,8 \%)$ de universidades privadas no tradicionales y 1 que corresponde a la federación de estudiantes mapuches (FEMAE). Esta nueva composición representó un cambio importante en los porcentajes de distribución que cada tipo de universidad tiene en este espacio.

Se puede reparar, del mismo modo, que el aumento de nuevas federaciones afiliadas y su diversificación, constituyen una fuente potencial de fragmentación y conflictividad interna en la estructura de la Confederación. En este sentido, el aumento en el número de federaciones y el ingreso de nuevos intereses corporativos, ha generado un juego interno más complejo, tanto para sostener los mecanismos formales e informales de coordinación, como para mantener los consensos entre universidades estatales y privadas. Estos factores agudizan las tensiones entre federaciones y aumentan los costos para la toma de decisiones estratégicas, incrementando la heterogeneidad interna del Pleno CONFECH, obstaculizando su capacidad ejecutiva y debilitando su competencia para articularse con el medio externo (gobierno, ciudadanía, medios de comunicación).

\section{Gestión política y gobernanza}

\section{Caracterización de actores}

La categorización permitió identificar cuatro grupos de actores políticos: a) las orgánicas cercanas al espectro neo-mirista, b) el bloque libertario y ex-Surda, c) las juventudes de los partidos de izquierda tradicional y d) la derecha gremial. A continuación, se caracterizan las orgánicas políticas asociadas a cada grupo. 
Marcelo Mella, Héctor Ríos, Ricardo Rivera, Condiciones orgánicas y correlaciones de fuerza del movimiento estudiantil chileno. Una aproximación desde la Confech (2011-2015) / Organic conditions and strength correlations of chilean student movement. An approach from Confech (2011-2015), Revista Izquierdas, 27, abril 2016, ISSN 0718-5049, pp. 124-160

a) Las orgánicas políticas tributarias del neo-mirismo, se formaron en los años 90 después del quiebre del Movimiento de Izquierda Revolucionaria (MIR), estas organizaciones apelaron a una política insurreccional para la construcción del socialismo, con una militancia clandestina que promovía la estrategia del "poder popular". 58 A este repertorio se sumaron otras fracciones de partidos de la izquierda chilena como el Movimiento Juvenil Lautaro y el Frente Patriótico Manuel Rodríguez Autónomo (FPMR-A), de las cuales se originaron síntesis de nuevas orgánicas y referentes estudiantiles. ${ }^{59}$

En términos estratégicos, buscaron impulsar una política comunitaria y de ruptura frente a las ideas fuerza del modelo neoliberal. ${ }^{60}$ Rasgos diferenciales de estos referentes neomiristas han sido la autogestión de las comunidades y la instalación de prácticas de democracia directa, la articulación estratégica mediante actividades clandestinas, así como la estructuración interna mediante el modelo marxista-leninista de orgánicas celulares. A partir de las plataformas universitarias se articulan con actores colectivos independientes, constituyen y fortalecen referentes políticos autónomos de los partidos tradicionales. ${ }^{61}$ Sin embargo, a pesar de la tendencia a la autolimitación que caracterizó a estas organizaciones desde 1990, desde 2011 se produjo en estos referentes, una creciente propensión a disputar electoralmente las federaciones a nivel nacional y el espacio confederado. ${ }^{62}$ Entre estas organizaciones se encuentran: el Movimiento Popular Guatchuneit (MPG), el Grupo de Acción Popular (GAP), el Movimiento de Izquierda Revolucionaria (MIR), la Juventud Guevarista (JG), Fuerza Universitaria Rebelde (FUR) y la Juventud Rebelde (JR).

b) Por otra parte, se cuentan las organizaciones que nacieron en el proceso de lucha sectorial entre los años 1990 a 2015. Estos actores se formaron con miembros provenientes del Partido Comunista (PC), del Movimiento de Izquierda Revolucionario (MIR) y del Partido Socialista (PS) y cristalizaron en nuevas orgánicas de izquierda, entre éstas, los nuevos referentes libertarios y los colectivos de la Surda. ${ }^{63}$ Entre sus elementos identitarios se consignan la crítica a la izquierda tradicional y, en especial, a los partidos que conducen la transición, por eso, aparecen como colectivos universitarios de carácter horizontal, organizativamente diferenciados de toda expresión de política institucional. ${ }^{64}$

\footnotetext{
${ }^{58}$ El "poder popular" es un concepto que se aplica para la construcción de un fuerza política social capaz de establecer una nueva forma de relación entre personas, alejado de las lógicas del capitalismo. Una forma de poder paralelo al Estado. Este concepto es desarrollado en cierto sector de la izquierda chilena y especialmente por el MIR y puede ser profundizado en: Sebastián Leiva, op.cit. 2007; Victor Muñoz, op.cit. 2009 y Osvaldo Torres, op.cit. 2012.

${ }^{59}$ Rivera, op.cit.

${ }^{60}$ Beatriz Silva. La Revolución Pingüina y el cambio cultural en Chile. Buenos Aires, CLACSO, 2007. Torres, op.cit.

${ }^{61}$ Silva, op.cit.

${ }^{62}$ Rivera, op.cit.

${ }^{63}$ Rivera, op.cit. Muñoz, op.cit. Avendaño, op.cit.

${ }^{64}$ Muñoz, op.cit. 2009; Avendaño, op.cit. 2014; Rivera, op.cit. 2015. Francisco Ramírez. Arriba los que luchan: un relato del comunismo libertario en Chile. 1997-2011. Memoria para optar al título de Periodista, Instituto de la Comunicación e Imagen, Universidad de Chile, Santiago de Chile, 2013, 9.
} 
Marcelo Mella, Héctor Ríos, Ricardo Rivera, Condiciones orgánicas y correlaciones de fuerza del movimiento estudiantil chileno. Una aproximación desde la Confech (2011-2015) / Organic conditions and strength correlations of chilean student movement. An approach from Confech (2011-2015), Revista Izquierdas, 27, abril 2016, ISSN 0718-5049, pp. 124-160

La principal estrategia de este sector es la articulación y unión del movimiento popular a través de los espacios sindicales y de las organizaciones de pobladores y estudiantes. ${ }^{65} \mathrm{De}$ tal suerte, la disputa de las federaciones se vuelve una necesidad estratégica para poder reproducir su proyecto. Sin embargo, estos grupos añaden a su tesis básica de articulación horizontal, la necesidad de proyectarse en lo político institucional mediante la disputa electoral. El objetivo es generar un movimiento popular fuerte y de potencialidad mayoritaria que pueda rebasar la institucionalidad desde dentro y desde afuera, con el propósito de generar condiciones políticas para la "ruptura democrática" y la superación del modelo de reproducción social vigente ${ }^{66}$. Entre las organizaciones que tienen mayor presencia en la CONFECH y pertenecen a este sector, se destacan el Frente de Estudiantes Libertarios (FEL), la Izquierda Autónoma (IA) y la Unión Nacional Estudiantil (UNE).

c) Las juventudes de los partidos de la izquierda tradicional, optaron por canalizar las demandas estudiantiles en coordinación con los gobiernos de la Concertación y, posteriormente, de la Nueva Mayoría (NM). En este sentido, estos actores se orientaron a la política institucional pero manteniendo una presencia estratégica en el movimiento popular, por esta razón, se argumenta que ocupan una posición de intermediación que corresponde al centro politico de la multifederativa. Este grupo se configuró en el año 2011 como actor clave de la oposición social y política, cuando las fuerzas alineadas de la Concertación y el PC se movilizaron contra el gobierno de Sebastián Piñera y la Alianza. ${ }^{67}$

Desde este bloque, la CONFECH es vista como una herramienta para potenciar el desempeño de la oposición social y política frente al gobierno. A través de la presión social se busca influir sobre el sentido común de los sectores medios y disputar el control de las políticas sectoriales a los grupos más conservadores del parlamento. Pero por sobre todo, el espacio estudiantil universitario se transforma en una arena política de contestación y resistencia frente al gobierno de Piñera. Una vez recuperado el gobierno por la Nueva Mayoría en marzo de 2014, el espacio confederado transitó, desde una lógica de resistencia a una de proyecto; desde una configuración defensiva (autolimitada) a una ofensiva, lo que proyectó a la CONFECH como actor estratégico del sistema político y de la política pública. Este paso desde una posición defensiva a una ofensiva, aparece reflejada en la expresión de Camila Vallejo: "Un pie en la calle y otro en el gobierno", que resume cierta creencia extendida de los partidos de la izquierda tradicional, respecto del lugar del PC en el segundo gobierno de Michelle Bachelet.

\footnotetext{
${ }^{65}$ Rivera, op.cit. 2015. Ramírez, op.cit. 2013. Max Urrutia y Pablo Seguel. "La estrategia de poder popular y de ruptura democrática. Práctica y pensamiento político nuestramericano”. En: GESP (coord.). Movimientos sociales y poder popular en Chile. Retrospectivas y proyecciones políticas de la izquierda latinoamericana. Santiago, Tiempo robado editoras. 2015.

${ }^{66}$ La tesis de Ruptura Democrática plantea la "irreformabilidad" del modelo en Chile. Ante esta situación, es necesario desarrollar y apoyar las distintas luchas del movimiento popular para conducir procesos de empoderamiento a los actores en lucha. A esta estrategia se le suma una serie de repertorios tácticos que van desde lo electoral hasta la insurrección de las masas.

${ }^{67}$ Avendaño, op.cit.
} 
Marcelo Mella, Héctor Ríos, Ricardo Rivera, Condiciones orgánicas y correlaciones de fuerza del movimiento estudiantil chileno. Una aproximación desde la Confech (2011-2015) / Organic conditions and strength correlations of chilean student movement. An approach from Confech (2011-2015), Revista Izquierdas, 27, abril 2016, ISSN 0718-5049, pp. 124-160

En este sentido, para las juventudes de estos partidos existió un doble desafío estratégico: enfrentarse con las distintas fuerzas que estaban en el espacio federativo, arrastrando el precio de la desconfianza por ser expresiones de actores institucionales y, por otro, enfrentarse con las fuerzas conservadoras dentro de la coalición del nuevo gobierno. ${ }^{68}$ Entre las juventudes que participan de este bloque se encuentran: las Juventudes Comunistas (JJCC), las Juventudes Socialistas (JS), las Juventudes del Partido por la Democracia (JPPD) y Nueva Acción Universitaria (NAU).

d) Por último, los sectores de derecha dentro del espacio estudiantil. El grupo de partidos de derecha representan una minoría durante este período en la Confederación, pero mantienen una presencia constante y estratégica en las dos principales federaciones a nivel nacional; la Universidad de Chile y la Pontificia Universidad Católica de Chile. ${ }^{69}$

Este conjunto de orgánicas promueve la consolidación del modelo de mercado en la educación, con correcciones específicas, por este motivo, rechazan las reformas pro gratuidad y la prohibición del lucro en las instituciones educativas. (El Mostrador, 2014) Por ende, sus programas apuntan en dirección contraria a la mayor parte de las federaciones afiliadas a la CONFECH. La derecha, dentro del espacio confederado, supone que los mayores problemas del sistema educacional chileno, consiste en la falta de un regulador más efectivo, así como, incentivos correctamente focalizados. El principal actor en este campo son los Gremialistas, organización identificada con referentes de la derecha católica integrista, en especial, con sectores de la UDI que poseen fuerte tradición al interior de la PUC. Sin embargo, también se pueden sumar a este sector, las Juventudes de la Democracia Cristiana (JDC), Nueva Corriente Regionalista (NCR) y Alternativa Liberal (AL).

\section{Correlaciones de fuerzas}

Para distinguir las posiciones de las fuerzas políticas, hemos considerado los criterios generales que surgen del esquema de Gerardo Munk presentado anteriormente (dilema "identidad" y "estrategia"), complementado con descriptores específicos. ${ }^{70}$ Las "posiciones" para los actores del espacio confederado son: "derecha", "centro", "izquierda" y "ultraizquierda" (Tabla $\mathrm{N}^{\circ}$ 2) y son tratadas como "locus" que conectan significados (recursos heurísticos) con lógicas particulares y patrones de comportamientos común entre actores. Evidentemente, el posicionamiento de un actor es afectado por el contexto anual, puesto que las organizaciones, aunque sean parte de un mismo referente, viven dinámicas de antagonismo con ciertas dimensiones comunes a nivel nacional $\mathrm{y}$, con tonos específicos, referidos a las características del enfrentamiento interno en cada institución universitaria.

\footnotetext{
${ }^{68}$ Síntesis del Encuentro Nacional Universitario de las Juventudes Comunista de Chile.

${ }^{69}$ Muñoz, op.cit. y Avendaño, op.cit.

${ }^{70}$ Munk, op.cit. 1995.
} 
Marcelo Mella, Héctor Ríos, Ricardo Rivera, Condiciones orgánicas y correlaciones de fuerza del movimiento estudiantil chileno. Una aproximación desde la Confech (2011-2015) / Organic conditions and strength correlations of chilean student movement. An approach from Confech (2011-2015), Revista Izquierdas, 27, abril 2016, ISSN 0718-5049, pp. 124-160

Tabla $\mathrm{N}^{\circ}$ 2: Criterios para el posicionamiento ideológico

\begin{tabular}{lll}
\hline Posición & Identidad & Estrategia \\
\hline Derecha & Legitimadora & Integración \\
Centro & $\begin{array}{l}\text { De proyecto (reformas } \\
\text { sectoriales) }\end{array}$ & Articulación \\
Izquierda & $\begin{array}{l}\text { De proyecto (reformas } \\
\text { régimen político) }\end{array}$ & Ruptura \\
Ultra-izquierda & $\begin{array}{l}\text { De resistencia } \\
\text { Insurrección }\end{array}$
\end{tabular}

Fuente: Elaboración en base a informes de fuerzas políticas y actas CONFECH

Tal como se aprecia en la tabla $\mathrm{N}^{\circ}$ 2, aparecen como alternativas en el criterio "identidad", las subcategorías "legitimadora" (identidad que reproduce, en lo esencial, la estructura de dominación), "de proyecto" (identidad que busca transformar la estructura de dominación, sea mediante reformas sectoriales, o a través de cambios en el sistema de relaciones de poder), y "de resistencia" (identidad que busca preservar o defender a sujetos devaluados y amenazados por la estructura de dominación actual).

En términos de las "estrategias" predominantes en cada posición, la derecha se caracteriza por un énfasis en la "integración" (pérdida de autonomía de las organizaciones estudiantiles y reproducción de intereses partidarios ligados al sector). Las organizaciones ubicadas en la posición centro aparecen orientadas a desempeñar un rol de "articulación" (con partidos con representación parlamentaria o mediante la función de intermediación en el espacio CONFECH). La izquierda se caracteriza por defender una estrategia de "ruptura" con el régimen político pre-existente (lo que implica predominancia de tácticas de presión por sobre la negociación), Finalmente, la ultra-izquierda se distingue por el uso preferente, sino exclusivo, de estrategias de carácter "insurreccional" (sin ninguna forma de dialogo o negociación con actores institucionales).

La Tabla $\mathrm{N}^{\circ} 3$ presenta el posicionamiento de los actores del espacio con sus respectivos criterios y descriptores específicos para clarificar la distribución del espacio en términos de la identidad y estrategia utilizada: 
Marcelo Mella, Héctor Ríos, Ricardo Rivera, Condiciones orgánicas y correlaciones de fuerza del movimiento estudiantil chileno. Una aproximación desde la Confech (2011-2015) / Organic conditions and strength correlations of chilean student movement. An approach from Confech (2011-2015), Revista Izquierdas, 27, abril 2016, ISSN 0718-5049, pp. 124-160

Tabla $N^{\circ}$ 3: Posicionamiento de actores $2011-2015$.

\begin{tabular}{|c|c|c|}
\hline POSICION & DESCRIPTORES & ORGANIZACIONES \\
\hline DERECHA & $\begin{array}{l}\text { Identidad Legitimadora + } \\
\text { Estrategia de Integración: } \\
\text { A favor de la regulación y } \\
\text { mayor financiamiento a las } \\
\text { universidades. Actores con } \\
\text { vínculos con los partidos de } \\
\text { derecha o que representan el } \\
\text { polo conservador de la Nueva } \\
\text { Mayoría. }\end{array}$ & $\begin{array}{l}\text { Acción Liberal (AL) } \\
\text { Juventud Demócrata Cristiana (JDC) } \\
\text { Gremialistas }\end{array}$ \\
\hline CENTRO & $\begin{array}{l}\text { Identidad de Proyecto } \\
\text { (reformas sectoriales) + } \\
\text { Estrategia de Articulación: } \\
\text { Apoyan el programa del } \\
\text { gobierno de la Nueva Mayoría. } \\
\text { A través de la disputa interna } \\
\text { dentro del conglomerado y la } \\
\text { presión externa del movimiento } \\
\text { estudiantil. }\end{array}$ & $\begin{array}{l}\text { Juventudes Comunistas (JJCC) } \\
\text { Juventudes Socialistas (JS) } \\
\text { Juventud Partido por la Democracia } \\
\text { (JPPD) } \\
\text { Nueva Acción Universitaria (NAU) }\end{array}$ \\
\hline IZQUIERDA & $\begin{array}{l}\text { Identidad de Proyecto } \\
\text { (reformas régimen político) + } \\
\text { Estrategia de Ruptura: } \\
\text { Avanzar en mayores grados de } \\
\text { democratización, a partir de la } \\
\text { movilización de masas y el } \\
\text { dialogo con presión hacia las } \\
\text { autoridades de gobierno. }\end{array}$ & $\begin{array}{l}\text { Unión Nacional Estudiantil (UNE) } \\
\text { Frente de Estudiantes Libertarios (FEL) } \\
\text { Izquierda Autónoma (IA) }\end{array}$ \\
\hline $\begin{array}{c}\text { ULTRA- } \\
\text { IZQUIERDA }\end{array}$ & $\begin{array}{l}\text { Identidad de Resistencia + } \\
\text { Estrategia de Insurrección: } \\
\text { Organizaciones autolimitadas. } \\
\text { Su proyecto busca instalar } \\
\text { clivajes para levantar un } \\
\text { movimiento de carácter } \\
\text { insurreccional. }\end{array}$ & $\begin{array}{l}\text { Movimiento Popular Guachuneit (MPG) } \\
\text { Grupos Acción Popular (GAP) } \\
\text { Movimiento de Izquierda } \\
\text { Revolucionario (MIR) } \\
\text { Frente Estudiantil Revolucionario (FER) } \\
\text { Juventud Guevarista (JG) } \\
\text { Partido de Trabajadores Revolucionarios } \\
\text { (PT) } \\
\text { Fuerza Universitaria Rebelde (FUR) } \\
\text { Juventud Rebelde (JR) } \\
\text { Corriente Crítica Universitaria (CCU) }\end{array}$ \\
\hline
\end{tabular}

Fuente: Elaboración en base a informes de fuerzas políticas y actas $\mathrm{CONFECH}$

El proceso político nacional de la CONFECH, está condicionado por la permanente transformación de las correlaciones entre los distintos sectores y orgánicas. Lo anterior debe entenderse en el contexto de procesos dinámicos de rotación de liderazgos propios del carácter contingente de la organización estudiantil. Las membresías políticas de los integrantes de las diferentes organizaciones constituyen campos de producción y 
Marcelo Mella, Héctor Ríos, Ricardo Rivera, Condiciones orgánicas y correlaciones de fuerza del movimiento estudiantil chileno. Una aproximación desde la Confech (2011-2015) / Organic conditions and strength correlations of chilean student movement. An approach from Confech (2011-2015), Revista Izquierdas, 27, abril 2016, ISSN 0718-5049, pp. 124-160

reproducción de significados o "universales", en contextos de alta heterogeneidad, fragmentación y conflictividad. Los cambios en la conducción del espacio desde 2011, significaron un desplazamiento expresivo y simbólico que se manifiesta, primariamente, a nivel discursivo.

Como se observa en la Tabla $\mathrm{N}^{\circ}$ 3, la ubicación de las organizaciones depende de los criterios identidad / estrategia, así como de las subcategorías respectivas. Al tratarse (criterios y subcategorías) de tipos ideales y de organizaciones que actúan en un espacio sometido a la contingencia y con importantes grados de informalidad, no existe una correspondencia total entre estos significantes y las características de los actores. Asimismo, se aprecia que, de las cuatro posiciones en las que se divide este espacio político, en la ultra-izquierda existe mayor aumento de organizaciones y, en consecuencia, mayor fragmentación. Todo esto impide considerar el crecimiento numérico como condición suficiente para una mayor capacidad de actuación (dado que este sector ha participado marginalmente en las vocerías nacionales y la Mesa Ejecutiva). En este contexto, el Pleno se constituye en un campo de fuerzas estructurado mediante la agregación de intereses de los espacios locales y de repertorios estratégicos que las fuerzas políticas utilizan para maximizar su poder a nivel nacional. No es posible, sin embargo, proyectar la diferenciación en la elaboración de estrategias observadas en el Pleno a cada uno de los espacios decisionales locales (espacios de cada federación, Zonales, otras estructuras de coordinación como FEMAE y vocerías de universidades privadas).

En el gráfico $\mathrm{N}^{\circ} 2$ se observa la evolución 2011-2015 en las correlaciones de fuerzas entre organizaciones políticas en el espacio CONFECH, específicamente, se identifican las siguientes tendencias:

a) El porcentaje de federaciones independientes disminuye, lo que podría interpretarse como resultado de una creciente polarización interna de las organizaciones estudiantiles. Hemos considerado entre las federaciones independientes aquellas que no están controladas por referentes políticos con expresión nacional o que representan a grupos políticos que no han logrado asegurar continuidad por más de un período de administración en su espacio local.

b) El centro político disminuye porcentualmente, evidenciando un proceso de retracción de apoyos para las organizaciones de partidos con representación parlamentaria adscritos a la Concertación y, posteriormente, a la Nueva Mayoría. Este fenómeno tiene efectos políticos paradojales dado que, por una parte, constituye una evidencia de la pérdida de anclaje y control sobre la arena universitaria del Partido Comunista, del Partido Socialista, del Partido por la Democracia y de la Democracia Cristiana. Al mismo tiempo, manifiesta la entrada de nuevas organizaciones que modifican las lógicas, correlaciones y modos de interacción en el espacio Confederado. Considerando el Pleno como un subsistema, la disminución del centro político representa una menor capacidad de intermediación y mayor fuerza centrífuga en la competencia interna entre los diferentes actores. 
Marcelo Mella, Héctor Ríos, Ricardo Rivera, Condiciones orgánicas y correlaciones de fuerza del movimiento estudiantil chileno. Una aproximación desde la Confech (2011-2015) / Organic conditions and strength correlations of chilean student movement. An approach from Confech (2011-2015), Revista Izquierdas, 27, abril 2016, ISSN 0718-5049, pp. 124-160

c) El conjunto de organizaciones reunidas en el bloque de izquierda aumenta de modo significativo durante el período, transformándose en el sector hegemónico que sustituye a la JJCC, después del 2011, en la conducción del espacio. Sin embargo, la capacidad de este sector de liderar la CONFECH está condicionada por el mantenimiento de la coalición de la UNE, IA y FEL ("Bloque de Conducción") que hace posible la gobernabilidad del Pleno y determina la capacidad de gestión política de la Mesa Ejecutiva. Durante el período de cuatro años (2012 a 2015) en que la coalición UNE, IA y FEL, constituyó una mayoría orgánica se observa una clara diferenciación interna entre los tres referentes, ya sea por el liderazgo del espacio o por los beneficios obtenidos en dicha alianza.

d) La derecha y la ultraizquierda experimentan un aumento marginal durante el período 2011-2015. En ambos casos, se trata de sectores internamente fragmentados por diferencias profundas en el "modelo originario" de cada organización, en sus vinculaciones con actores externos, en los repertorios ideológicos y en sus definiciones estratégicas y tácticas. Por ejemplo, aunque sectorialmente sean parte de la derecha del movimiento: Acción Liberal (AL), Gremialistas y la Juventud Demócrata Cristiana (JDC), no es posible, a partir de la ubicación común en el contexto del sistema político universitario, que estos actores constituyan un bloque orgánico o una alianza política efectiva. Como se podrá entender, AL y Gremialistas, aunque no constituyan "antípodas" ideológicas, al menos su relación implica tensiones que obstaculizan la convergencia de ambos. Por su parte, la JDC difiere de los dos grupos anteriores por razones estratégicas y por su vinculación a la Concertación y a la Nueva Mayoría. Lo propio ocurre en la ultraizquierda entre movimientos de orientación trotkista y leninista.

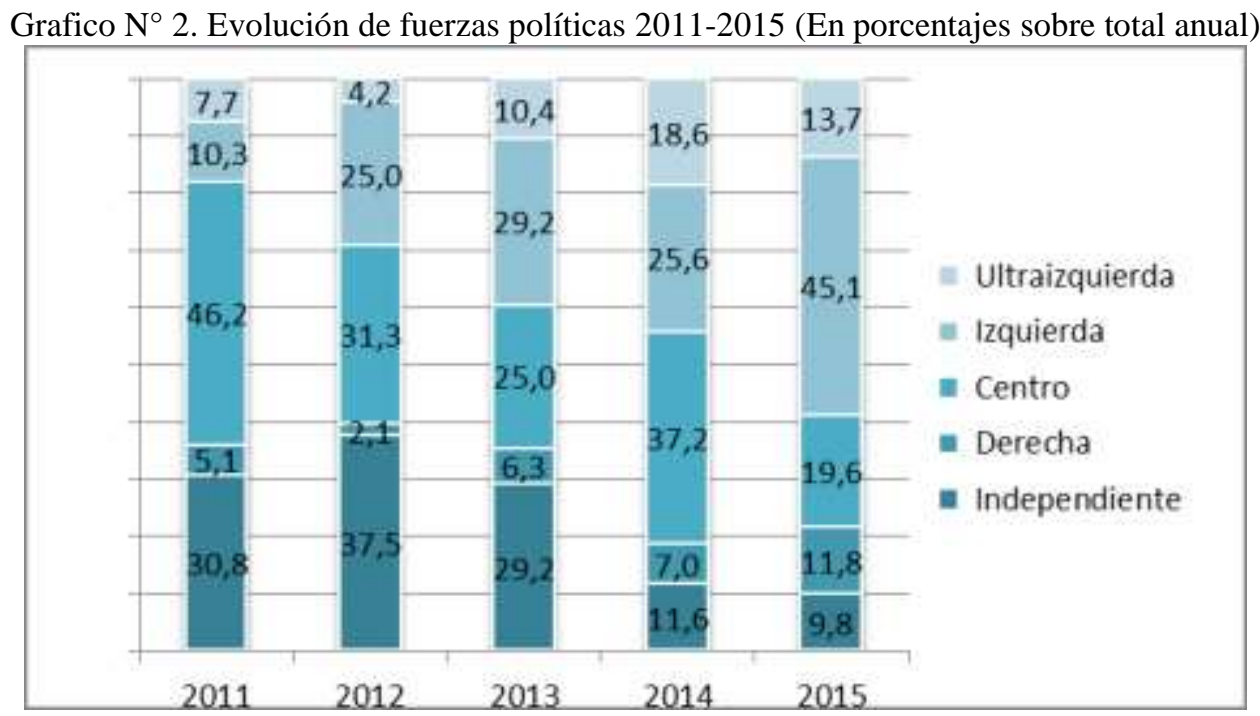

Fuente: Elaboración en base a informes de fuerzas políticas y actas $\mathrm{CONFECH}$ 
Marcelo Mella, Héctor Ríos, Ricardo Rivera, Condiciones orgánicas y correlaciones de fuerza del movimiento estudiantil chileno. Una aproximación desde la Confech (2011-2015) / Organic conditions and strength correlations of chilean student movement. An approach from Confech (2011-2015), Revista Izquierdas, 27, abril 2016, ISSN 0718-5049, pp. 124-160

En las macrotendencias se observa una creciente polarización del espacio confederado y un debilitamiento del centro, tanto en su capacidad movilizadora, como en su capacidad de intermediación. En esta perspectiva, la polarización progresiva podría ser consecuencia de la pérdida de anclaje de las estructuras partidarias tradicionales, así como el debilitamiento del centro puede ser interpretado como desplazamiento de una cultura política consensual por una más orientada al conflicto, generando ambos procesos, mayores exigencias para la gestión política y la gobernanza de la Mesa Ejecutiva. Existe, en estos años, un rápido proceso de corrimiento de las orgánicas políticas a la izquierda, como reacción al inmovilismo institucional que caracterizó al sistema político en la década de 1990.

Grafico $\mathrm{N}^{\circ}$ 3. Tendencias ascendentes y declinantes en el espacio

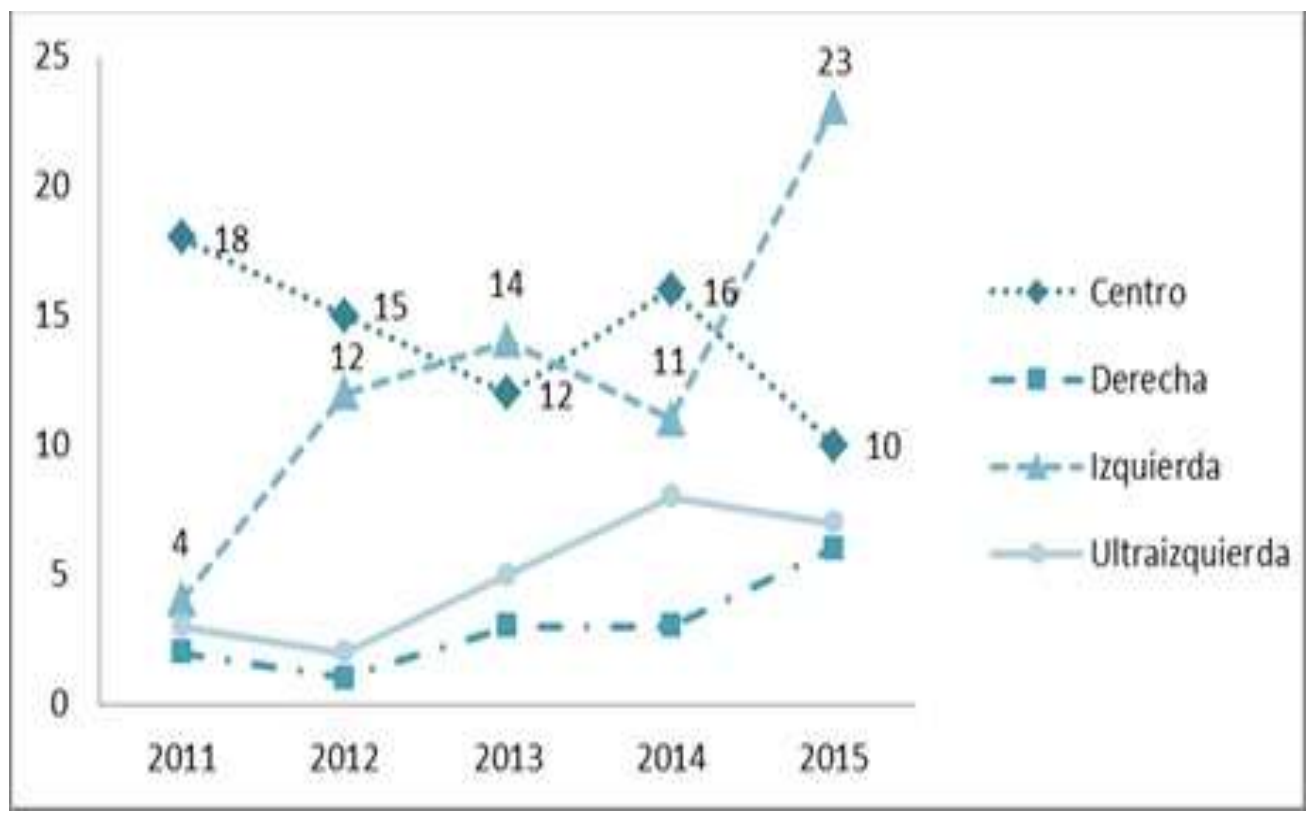

Fuente: Elaboración en base a informes de fuerzas políticas y actas CONFECH

Los grupos que tienen mayor representación política son las organizaciones de centro, izquierda y ultraizquierda. A pesar de esto, la relación de alianza y trabajo entre las orgánicas por bloque, no siempre funciona como pactos, por tanto, no se manifiesta, necesariamente, como cooperación sistemática entre referentes. En algunos momentos los referentes políticos cambian en su posicionamiento, ya sea por cambios en sus programas y estrategias o por el peso de responder a la contingencia y al escenario político nacional. Se puede apreciar como distintas orgánicas políticas, representadas por diferentes bloques, levantan con distinta intensidad demandas locales o reivindicaciones con una articulación territorial más amplia.

Para el período 2011 a 2015 observamos (Grafico N³) una transición en el espacio CONFECH desde la hegemonía del centro, esto es, predominio JS y JJCC, a la hegemonía de la izquierda, vale decir, predominio de nuevos referentes como UNE, IA y FEL 
Marcelo Mella, Héctor Ríos, Ricardo Rivera, Condiciones orgánicas y correlaciones de fuerza del movimiento estudiantil chileno. Una aproximación desde la Confech (2011-2015) / Organic conditions and strength correlations of chilean student movement. An approach from Confech (2011-2015), Revista Izquierdas, 27, abril 2016, ISSN 0718-5049, pp. 124-160

constituidos en el denominado "Bloque de Conducción". Al mismo tiempo, en la medida que estos nuevos actores acceden a espacios de poder federativo, se produce, en cierto número de ellos, una evolución estratégica que tensiona la relación entre las retóricas y las estrategias. Este fenómeno resulta de especial interés en la ultraizquierda considerando fenómenos de expansión como MPG y JG.

Aunque el recambio en la hegemonía del espacio confederado resulta evidente, distinguimos entre la capacidad de una orgánica (o un conjunto de ellas) para ganar las elecciones internas en cada espacio federativo (tema que no es abordado en este trabajo), capacidad para instalar a su referente en la Mesa Ejecutiva o capacidad para alcanzar un buen nivel de desempeño en la conducción del espacio confederado. Se puede apreciar en los gráficos 2 y 3 que, si bien la izquierda y la ultra, agregadamente, controlan un porcentaje mayoritario del espacio del Pleno, las diferentes maneras de posicionarse cada orgánica frente a lo estatal, así como las diversas subculturas políticas confieren a estos sectores alta heterogeneidad. Por tanto, la complejidad de la dinámica interna de cada organización y los modos de interacción entre el centro, la izquierda y la ultra constituyen cuestiones cruciales para entender su capacidad de conducción o su capacidad de veto.

\section{Tendencias de las fuerzas políticas}

Los gráficos $\mathrm{N}^{\circ}$ 4, 5 y 6 detallan el número de federaciones que cada orgánica política controló entre el año 2011 y el 2015. Durante este período las orgánicas de izquierda y ultraizquierda, exceptuando la IA, participaron en el espacio "Sin-FECH". ${ }^{71}$ Este espacio político paralelo a la CONFECH buscó contrarrestar el riesgo de cooptación o captura de la organizaciones universitarias por parte de los partidos de la Concertación situada en la oposición al gobierno de Piñera, a través de un control de los Zonales y de las elecciones federativas. ${ }^{72} \mathrm{El}$ Sin-FECH se convirtió en un espacio estratégico de contestación que reunió a los desafiantes de la Mesa Ejecutiva hegemonizada por la JJCC, con el objetivo de formar fuerza propia y crear un nuevo petitorio de demandas en búsqueda de cambios más profundos. En la fase final de la movilización del 2011, se formó la UNE, referente que en los años siguientes ganará una importante cantidad de federaciones a nivel nacional y, junto a organizaciones como el FEL y la IA, se transformarán en los principales actores estratégicos del movimiento.

Como se observa en el Gráfico $\mathrm{N}^{\circ}$ 4, durante el año 2011, la mayor cantidad de federaciones pertenece a las Juventudes Comunistas, que cuentan con doce federaciones (30,8\% sobre el total del Pleno) y, entre estas, con dos de las universidades con mayor número de estudiantes, la FECH (Universidad de Chile) y la FEUSACH (Universidad de Santiago). Entre 2011 y 2015 la JJCC cae desde un 30,8\% a un 11,8\%, evidenciando una abrupta pérdida de control del Pleno y de los espacios federativos a nivel nacional. El resto

\footnotetext{
${ }^{71}$ El Sin-FECH fue un espacio de agrupaciones políticas que estaban en contra de la política de conducción de las JJCC, IA y de RD durante el año 2011. Avendaño, op.cit.

${ }^{72}$ Rivera, op.cit. y Avendaño, op.cit.
} 
Marcelo Mella, Héctor Ríos, Ricardo Rivera, Condiciones orgánicas y correlaciones de fuerza del movimiento estudiantil chileno. Una aproximación desde la Confech (2011-2015) / Organic conditions and strength correlations of chilean student movement. An approach from Confech (2011-2015), Revista Izquierdas, 27, abril 2016, ISSN 0718-5049, pp. 124-160

de los referentes de este sector disminuyen su presencia en el sistema político universitario (La JS baja de 10,3\% en 2011 a $2 \%$ en 2015) o se mantienen en una condición de marginalidad, considerando la expansión de la multifederativa en los últimos cinco años (NAU se mantiene en un rango que va desde el $2 \%$ a un poco más del $4 \%$ ).

Grafico $\mathrm{N}^{\circ}$ 4. Orgánicas políticas: Bloque Centro.

(Porcentaje sobre el total de Federaciones del Pleno)

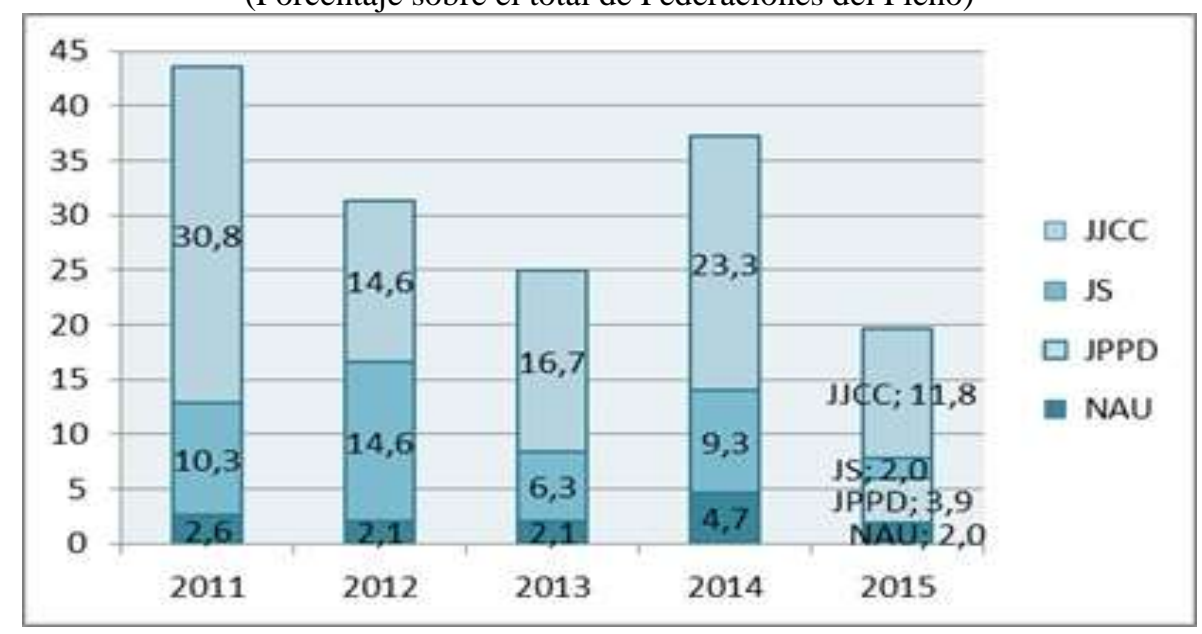

Fuente: Elaboración en base a informes de fuerzas políticas y actas CONFECH

Para el caso del bloque de izquierda, se observa un aumento significativo en el número de federaciones controladas por IA, FEL y UNE, proceso que permitirá dar gobernabilidad a la CONFECH entre 2012 y 2015. De las tres orgánicas, IA es la que experimenta menor crecimiento $(5,1 \%$ en 2011 a 9,8\% en 2015), aunque gana en tres oportunidades la presidencia de la FECH con Gabriel Boric (2012), Andrés Fielbaum (2013) y Valentina Saavedra (2015), lo que entrega a este referente liderazgo y control de la Mesa Ejecutiva. Como se observa en el gráfico 5, las otras dos orgánicas del sector experimentan mayor crecimiento en el número de federaciones, llegando a transformarse en referentes con presencia nacional (FEL crece desde un 2,6\% en 2011 a 15,7\% en 2015 y UNE pasa desde un 2,6\% en 2011 a 19,6\% en 2015). Sin embargo, solo el FEL llega en 2014 a disputar el liderazgo del bloque de conducción con el triunfo en la FECH de Melissa Sepúlveda. 
Marcelo Mella, Héctor Ríos, Ricardo Rivera, Condiciones orgánicas y correlaciones de fuerza del movimiento estudiantil chileno. Una aproximación desde la Confech (2011-2015) / Organic conditions and strength correlations of chilean student movement. An approach from Confech (2011-2015), Revista Izquierdas, 27, abril 2016, ISSN 0718-5049, pp. 124-160

Grafico $\mathrm{N}^{\circ} 5$ Orgánicas políticas: Bloque Izquierda.

(Porcentaje sobre el total de Federaciones del Pleno)

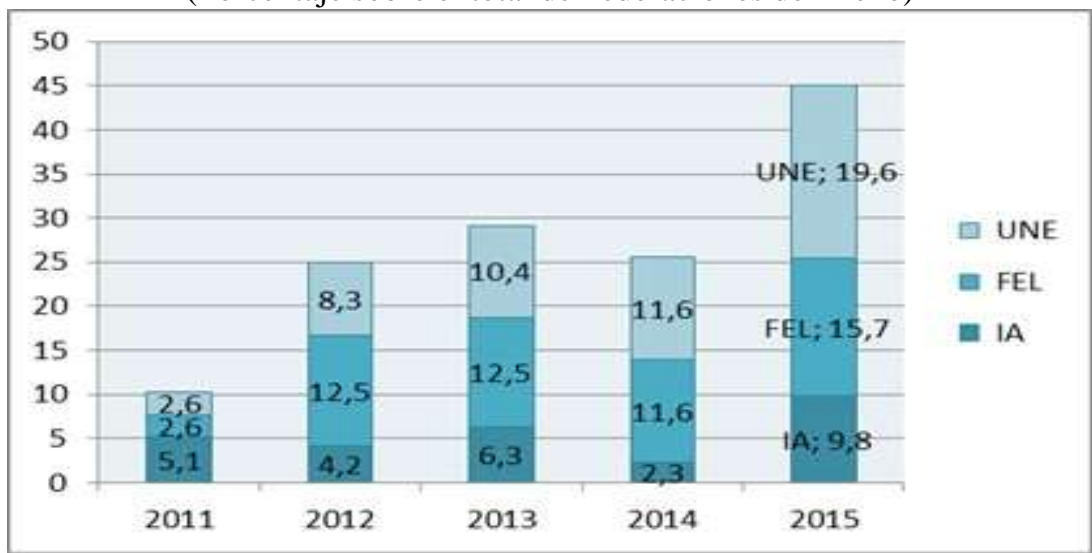

Fuente: Elaboración en base a informes de fuerzas políticas y actas $\mathrm{CONFECH}$

En relación a la Ultraizquierda se observa una tendencia a la fragmentación en el sector y un leve aumento en el porcentaje de las federaciones controladas por sus orgánicas. Como se aprecia en el gráfico 6, de todas las orgánicas, MPG es la que experimenta mayor crecimiento desde un 2,1\% en 2012 a 5,9\% en 2015, mientras el resto de los referentes (JG, MIR, JR, FUR) mantienen una presencia menor y estable en el espacio del Pleno. Los casos de CCU, GAP y PT se destacan por controlar federaciones solo durante el 2011. Todos estos procesos se pueden enmarcar interpretativamente, en el fuerte tradicionalismo estratégico y propensión al exclusivismo político que caracteriza al sector, produciendo la persistencia de un doble dilema no resulto en estos actores: i) elegir entre camino propio o alianzas sacrificando, en este último caso, características de la subcultura propia (dilema identidad / estrategia) y ii) elegir entre concentrarse en la expansión territorial (nacionalización) del referente o la focalización en federaciones claves por su importancia emblemática.

Grafico $N^{\circ} 6$ Orgánicas políticas: Bloque Ultraizquierda.

(Porcentaje sobre el total de Federaciones del Pleno)

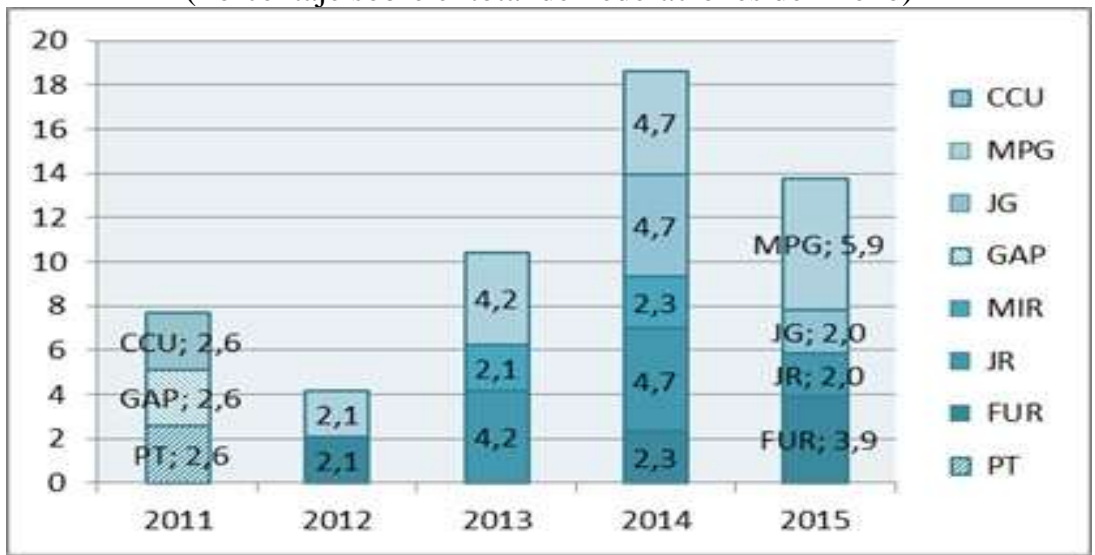

Fuente: Elaboración en base a informes de fuerzas políticas y actas CONFECH 
Marcelo Mella, Héctor Ríos, Ricardo Rivera, Condiciones orgánicas y correlaciones de fuerza del movimiento estudiantil chileno. Una aproximación desde la Confech (2011-2015) / Organic conditions and strength correlations of chilean student movement. An approach from Confech (2011-2015), Revista Izquierdas, 27, abril 2016, ISSN 0718-5049, pp. 124-160

\section{Discusión}

Como se visto, las transformaciones orgánicas y políticas al interior del espacio CONFECH desde el 2011 y el análisis de los reglamentos de sala, reflejan el fortalecimiento de los mecanismos ejecutivos, acompañado del aumento en el control interno sobre sus dirigentes (accountability vertical) y mayor desarrollo de mecanismos de control intermedio, correspondientes a los Zonales (accountability horizontal). Al mismo tiempo, se observa la entrada de grupos de presión informal al interior del espacio como las vocerías de universidades privadas y FEMAE que responden al crecimiento y complejización del Pleno. Este proceso, sin embargo, no estuvo acompañado de cambios orgánicos que permitieran actualizar el funcionamiento interno y generaran mecanismos eficaces para procesar tensiones y la creciente competitividad.

Estas tendencias muestran que durante los años que comprende el estudio, el espacio confederado soportó un proceso de desarrollo impulsado por coyunturas críticas en los gobiernos de Piñera y Bachelet. Sin embargo, estos cambios no implicaron un avance importante los niveles de institucionalización y coordinación. De modo tal, CONFECH mantiene su característica de espacio político, tendiente a la dispersión e informalidad y con funcionamiento institucional frágil, dependiente de las correlaciones de fuerzas contingentes, que hacen a la organización particularmente dependiente y permeable de las condiciones ambientales.

Otros resultados, referentes a las tendencias actorales, indican que se produce durante estos años un aumento en el tamaño de la Confederación, dado el ingreso de nuevas federaciones, situación que acrecienta la heterogeneidad y los costos de transacción al interior del Pleno. También se observa una diversificación de actores, generada por la afiliación masiva de federaciones de universidades privadas no tradicionales, proceso que tiene implicancias, no solo términos de gobernanza, sino además, determina orientaciones específicas de las demandas del movimiento estudiantil universitario. Por ejemplo, se percibe que la demanda por cambios estructurales de la educación universitaria en el 2011, da paso a un movimiento de los actores hacia la demanda por gratuidad, fenómeno que coexiste con la incorporación de federaciones de universidades privadas no tradicionales.

Respecto al encadenamiento entre las correlaciones de fuerza y la gobernanza de este espacio, los procesos descritos han generado un aumento en los costos de la toma de decisiones y la coordinación colectiva que ha complejizado la capacidad de gestión política de la Mesa Ejecutiva. Uno de los síntomas de esta mayor complejidad organizativa se manifiesta con la transición desde un Pleno controlado por organizaciones políticas dependientes de partidos con representación parlamentaria bajo hegemonía de la JJCC, a un segundo momento desde 2012, en el que la hegemonía de la Mesa Ejecutiva y el control del Pleno pasa a manos de una coalición de nuevos referentes conocida como "Bloque de Conducción". 
Marcelo Mella, Héctor Ríos, Ricardo Rivera, Condiciones orgánicas y correlaciones de fuerza del movimiento estudiantil chileno. Una aproximación desde la Confech (2011-2015) / Organic conditions and strength correlations of chilean student movement. An approach from Confech (2011-2015), Revista Izquierdas, 27, abril 2016, ISSN 0718-5049, pp. 124-160

Dicho desarrollo en que los referentes políticos tradicionales pierden centralidad en el espacio CONFECH plantea la interrogante acerca de la capacidad de las nuevas organizaciones políticas para generar impacto en el proceso de política pública. Evidentemente, el desplazamiento de la JJCC y la llegada del "Bloque de Conducción", generó efectos intencionales como el reforzamiento del anclaje y control del Pleno, pero del mismo modo, produjo efectos no intencionales, como una menor capacidad de incidir en el debate legislativo y en las políticas sectoriales.

Por otra parte, en el esquema del Bloque de Conducción vigente desde 2012, las orgánicas políticas, de manera individual, pocas veces controlaron mayor porcentaje de federaciones que la JJCC en 2011, siendo, en consecuencia, mayor la necesidad de las mesas ejecutivas lideradas por IA, UNE y FEL de disponer de una coalición operativa para el control del Pleno.

Asimismo, del análisis realizado se concluye que el creciente número de organizaciones ubicadas en el bloque de la ultra-izquierda se relaciona con mayores costos organizativos para construir alianzas debido a las siguientes complejidades: a) la débil institucionalidad formal de la CONFECH promueve entre los actores estrategias de sobrevivencia y autoafirmación en contextos de rápida renovación de dirigencias, y b) la cultura política en este sector tiende al expresivismo y al mesianismo (identidad), más que a la racionalidad instrumental (estrategia) de largo plazo, generando en estas organizaciones, importantes restricciones en términos de acumulación de experiencias y aprendizaje político.

La información examinada permite sostener que el crecimiento y diversificación actoral constituyen factores de riesgo permanente que tensiona los mecanismos de gobernanza formales e informales, aumentando los costos de toma de decisiones y los procesos de negociación entre organizaciones. Desde la perspectiva de los procesos de institucionalización y sus dilemas, esta tendencia constituye una demanda de estratégicas, asociada a la gobernabilidad y sustentabilidad interna del espacio, por sobre la demandas del contexto político asociadas a la reformas y la definición de políticas públicas sectoriales. Esta conclusión permite señalar que los esfuerzos políticos de las fuerzas integrantes de la Mesa Ejecutiva ("Bloque de Conducción”) se han concentrado en los problemas de gobernabilidad internos, por sobre la construcción de agenda; proceso que permite ubicar a la Confederación como un actor cuya mayor vulnerabilidad se vincula a la cooptación por el Estado y sus instituciones, como así también, a las tendencias implosivas producto de la creciente fragmentación política interna.

Finalmente, la mayor centralidad política de la problemática educacional afecta los grados de autonomía del movimiento de manera diferencial. Nuestro análisis de la documentación de fuerzas políticas permite afirmar a modo hipotético, que el desempeño electoral de las organizaciones condiciona los procesos de construcción identitaria y de elección de estrategias. El proceso de crecimiento y fragmentación experimentado por el espacio CONFECH desde 2011 a 2015 permite concluir también que el capital en disputa no solo 
Marcelo Mella, Héctor Ríos, Ricardo Rivera, Condiciones orgánicas y correlaciones de fuerza del movimiento estudiantil chileno. Una aproximación desde la Confech (2011-2015) / Organic conditions and strength correlations of chilean student movement. An approach from Confech (2011-2015), Revista Izquierdas, 27, abril 2016, ISSN 0718-5049, pp. 124-160

corresponde a aquellos recursos producidos internamente, sino a la valorización externa del juego político desarrollado en la lucha interna del movimiento. Esto significa que existirían transacciones rutinarias entre este espacio y el sistema político general, independiente de qué actores controlan la Mesa Ejecutiva y el Pleno. Por cierto, los recursos de poder, el capital simbólico y la relevancia de las demandas estudiantiles son valorizadas por el conjunto de la sociedad. Como también, las organizaciones políticas estudiantiles en su propósito de controlar su reproducción, buscan establecer ventajas con sus competidores utilizando recursos de la política institucional. En consecuencia, parece configurarse la paradoja de que a medida que las organizaciones estudiantiles alcanzar un mejor desempeño electoral y logran controlar el Pleno CONFECH, son crecientemente permeadas por múltiples recursos de la política institucional que debilitan su autonomía y sus idiosincrasias originales orientadas al cambio.

\section{Bibliografia}

\section{Libros y artículos}

Rafael Agacino. "Movilizaciones estudiantiles en Chile. Anticipando el futuro". Educação em Revista, Marília, Vol. 14, n. 1, p. 7-20, Jan.-Jun., 2013.

Aguilera, O. (2011). "Movidas, movilizaciones y movimientos de juventudes". En Latinoamericamente. Santiago, Editorial Quimantú. 119-129.

Aguilera, O. (2012). "Repertorios y ciclos de movilización juvenil en Chile (2000-2012)". Utopía y Praxis: Revista internacional de filosofía iberoamericana y teoría social, 57, 2012, 101 - 108.

Avendaño, O. (2014). "Fracturas y representación política en el movimiento estudiantil: Chile 2011". Última década, 22(41), 41-68. Recuperado en 05 de agosto de 2015, de http://www.scielo.cl/scielo.php?script=sci_arttext\&pid=S0718-

$22362014000200003 \& \operatorname{lng}=$ es\&tlng=es. 10.4067/S0718-22362014000200003

Bevir, M. y Rhodes, R. (2001). "A Decentred Theory of Governance: Rational Choice, Institucionalism and Interpretation". Institute of Governmental Studies, Working Paper Núm. 10, University of California, Berkeley.

Boccardo, G y Ruiz, C. (2009). "Problemas sociales de la concentración económica (visto desde la crisis)". Revista Análisis. Departamento de Sociología de la Universidad de Chile, 12, p. 31-54.

Boccardo, G y Ruiz, C. (2012). "Peripecias del capital y el trabajo en el neoliberalismo avanzado". Revista Análisis. Departamento de Sociología de la Universidad de Chile, 15, p. 25-52.

Bonvecchi, A. (2006) "Determinismo y contingencia en las interpretaciones políticas de la crisis argentina". Revista SAAP, 2 (3): 509-536. 
Marcelo Mella, Héctor Ríos, Ricardo Rivera, Condiciones orgánicas y correlaciones de fuerza del movimiento estudiantil chileno. Una aproximación desde la Confech (2011-2015) / Organic conditions and strength correlations of chilean student movement. An approach from Confech (2011-2015), Revista Izquierdas, 27, abril 2016, ISSN 0718-5049, pp. 124-160

Bourdieu, P. (1985). ¿Qué significa hablar? Economía de los intercambios lingüísticos. Madrid, AKAL.

Bourdieu, P. (1999). Intelectuales, política y poder. Buenos Aires, EUDEBA.

Caplow, T. (1974) Dos contra uno: teoría de las coaliciones en las tríadas. Madrid, Alianza Editorial.

Cheibub, J. A. (2002) "Minority Governments, Deadlock Situations, and the Survival of Presidential Democracy”. Comparative Political Studies, 35 (3): 284-312.

Coppedge, M. (2001). "Instituciones y gobernabilidad democrática en América Latina”. En Antonio Camou. Los desafíos de la gobernabilidad. FLACSO-IISUNAM-Plaza y Valdés.

Fleet, N. (2011). "Movimiento estudiantil y transformaciones sociales en Chile: una perspectiva sociológica". Polis, 30, p. 2-13.

Flick, U. (2004). Introducción a la investigación cualitativa. Madrid: Morata.

Freidenberg, F. y Levitsky, S. (2007). "Organización informal de los partidos en América Latina”. Desarrollo Económico. 46.184: 539-568.

Garcés, M. (2011). "Movimientos Sociales e izquierda en América Latina: nuevas estrategias y nuevos movimientos”. En Latinoamericamente. Santiago, Editorial Quimantú. 19-32.

Garcés, M. (2012). El despertar de la sociedad. Santiago de Chile: LOM ediciones.

Garretón, M. (1984). "El movimiento estudiantil: conceptos e historia". Biblioteca del Movimiento Estudiantil. Tomo IV. Santiago de Chile. Ediciones SUR.

Garretón, M. (2011). "Movimiento social, nuevas formas de hacer política y enclaves autoritarios. Los debates del Consejo Asesor para la Educación en el gobierno de Michelle Bachelet en Chile". Polis, 10, p.117-140.

Helmke, G. y Levitsky, S. (2003) "Informal institutions and comparative politics: a research agenda". Perspectives on Politics. Volume 2 / Issue 04 / December 2004, 725-740. American Political Science Association DOI: http://dx.doi.org/10.1017/S1537592704040472 (About DOI), Published online: 01 December 2004

Hochstetler, K. (2008) "Repensando el presidencialismo: desafíos y caídas presidenciales en Sudamérica". América Latina Hoy, 49: 51-72.

Huntington, S. (1992). El orden político de las sociedades en cambio, Buenos Aires, Paidós, 1992 (edición original en inglés, 1968). 
Marcelo Mella, Héctor Ríos, Ricardo Rivera, Condiciones orgánicas y correlaciones de fuerza del movimiento estudiantil chileno. Una aproximación desde la Confech (2011-2015) / Organic conditions and strength correlations of chilean student movement. An approach from Confech (2011-2015), Revista Izquierdas, 27, abril 2016, ISSN 0718-5049, pp. 124-160

Leiva, S. (2007) "Teoría y práctica del poder popular: los casos del Movimiento de Izquierda Revolucionaria (MIR, Chile, 1970 - 1973) y el Partido Revolucionario de los Trabajadores Ejército Revolucionario del Pueblo (PRT - ERP, Argentina, 1973 - 1976)". Tesis de magister. Universidad de Santiago de Chile. Santiago. 2007.

Mainwating. S. y Scully, T. (1995). "La institucionalización de los sistemas de partido en América Latina”. Revista de Ciencia Política. Vol. XVII, Núm. 1-2.

Mainwaring, S. y Torcal, M. (2005). "La institucionalización de los sistemas de partidos y la teoría del sistema partidista después de la tercera ola democratizadora". América Latina Hoy, Vol. 41, diciembre 2005, 141-173.

March, J. G. y Olsen, J. P. (1984). "The new institutionalism: Organizational factors in political life". American Political Science Review, 78, 738-749.

Mayol, A y Azócar, C. (2011). "Politización del malestar, movilización social y transformación ideológica: el caso Chile 2011". Polis, 10, 163-184.

Mayol, A. (2012). No al Lucro. De la crisis del modelo a la nueva era política. Debate, Santiago. 2012.

Mella, M. (2012). Elementos de Ciencia Política. Conceptos, Actores y Procesos. Vol. 1, Santiago, RIL.

McCarthy J. D. y Zald, M.N. (1977). "Resource Mobilization and Social Movements: A Partial Theory”. American Journal of Sociology. 82.6, 1977, 1212-1241.

Mintzberg, H. (1984). La estructuración de las organizaciones. Editorial Aries: Barcelona.

Morlino, L. (2009). Democracia y democratizaciones. Madrid: Centro de Investigaciones Sociológicas (CIS).

Moulian, T. (2002). Chile Actual. Anatomía de un mito. LOM; Santiago.

Muñoz, V. (2009). "Generaciones en tránsito: Juventud universitaria e izquierdas políticas en Chile y México (Universidad de Chile- UNAM 1984-2006)”. Tesis doctoral. Universidad Nacional Autónoma de México. México.

Munck, G. (1995). "Algunos problemas conceptuales en el estudio de los movimientos sociales". Revista Mexicana de Sociología, Vol. 57, No. 3. (Jul. - Sep., 1995), pp. 17-40.

Munck, G. (1997). "Formação de Atores, Coordenação Social e Estratégia Política:. Problemas Conceituais hacen Estudo dos Movimentos Sociais". Revista Dados, 40 (1)

North, D. (1990). Institutions, Institutional Change and Economic Performance. Cambridge, Cambridge University Press. 
Marcelo Mella, Héctor Ríos, Ricardo Rivera, Condiciones orgánicas y correlaciones de fuerza del movimiento estudiantil chileno. Una aproximación desde la Confech (2011-2015) / Organic conditions and strength correlations of chilean student movement. An approach from Confech (2011-2015), Revista Izquierdas, 27, abril 2016, ISSN 0718-5049, pp. 124-160

Payne, M. (2006). La política importa. Democracia y desarrollo en América Latina. BID. Washignton D.C.

Peters, G. (2003). El nuevo institucionalismo. Barcelona, Gedisa.

Pérez-Liñán, A. (2008). "Instituciones, coaliciones callejeras e inestabilidad política: perspectivas teóricas sobre las crisis presidenciales". América Latina Hoy, 49. Recuperado de http://campus.usal.es/ revistas trabajo/index.php/1130-2887/article/view/1352/1423

Przeworski, A. (1995) Democracia y mercado. Reformas políticas y económicas en la Europa del Esta y América Latina. Cambridge, U.K., Cambridge University Press.

Ramírez, F. (2013). "Arriba los que luchan: un relato del comunismo libertario en Chile. 19972011". Memoria para optar al Título de Periodista. Escuela de Periodismo, Instituto de la Comunicación e Imagen, Universidad de Chile, Santiago.

Rivera, R. (2015). "Los Pilares Fundamentales del Movimiento Estudiantil en Chile: 2000-2014”. Tesis de pregrado para optar al Título de Periodista. Escuela de Periodismo. Universidad de Santiago de Chile. Santiago.

Rossi, J. (2012). "La movilización estudiantil chilena en 2011: una cronología”. OSAL Observatorio Social de América Latina, Año 13, $\mathrm{N}^{\circ} 31 . \quad$ Disponible en: http://biblioteca.clacso.edu.ar/clacso/osal/20120417105250/OSAL31.pdf

Salazar, G. (2012). Movimientos sociales en Chile. Santiago de Chile: Uqbar editores.

Siavelis, P. (1999). "Continuidad y transformación del sistema de partidos en una transición modelo". En: El modelo chileno. Democracia y desarrollo en los noventa, Santiago, LOM, 1999, 251.

Silva, B. (2007). La Revolución Pingüina y el cambio cultural en Chile. CLACSO, Buenos Aires, disponible en: http://bibliotecavirtual.clacso.org.ar/ar/libros/becas/2007/cultura/silva.pdf

Taagepera, R. (2007). "Electoral Systems". En Boix, C. y Stokes, S. The Oxford Handbook of Comparative Politics. Nueva York: Oxford University Press Inc.

Tejerina, B. (Octubre del 2005). "Movimientos sociales, espacio público y ciudadanía: Los caminos de la utopía”. Revista Crítica de Ciencias Sociales, 72, 67-97.

Tilly, Ch. y Wood, L. (2013). Los movimientos sociales. 1768-2008. Desde sus orígenes a Facebook. Barcelona, Critica.

Thielemann, L. (2011). "Para una periodificación del movimiento estudiantil de la transición (19872011)". En: Sistematización de Talleres para la Acción Estudiantil. CEFECH-Heinrich-BöllStiftung. Santiago.

Torres, O. (2012). Democracia y Lucha armada. MIR y MLN-Tupamaros. Santiago, Chile: Pehuén. 
Marcelo Mella, Héctor Ríos, Ricardo Rivera, Condiciones orgánicas y correlaciones de fuerza del movimiento estudiantil chileno. Una aproximación desde la Confech (2011-2015) / Organic conditions and strength correlations of chilean student movement. An approach from Confech (2011-2015), Revista Izquierdas, 27, abril 2016, ISSN 0718-5049, pp. 124-160

Touraine, A. (2006). “Los movimientos sociales”. Revista colombiana de sociología, 27, 255-278.

Urrutia, M. y Seguel, P. (2015) "La estrategia de poder popular y de ruptura democrática. Práctica y pensamiento político nuestramericano". En GESP (coord.), Movimientos sociales y poder popular en Chile. Retrospectivas y proyecciones políticas de la izquierda latinoamericana, Santiago, Tiempo robado editoras.

Zibechi, R. (2003): "Los movimientos sociales latinoamericanos: tendencias y desafíos". OSAL: Observatorio Social de América Latina. No. 9. Buenos Aires: CLACSO. Recuperado de: http://bibliotecavirtual.clacso.org.ar/ar/libros/osal/osal9/zibechi.pdf

\section{Periódicos}

Diario La Tercera.

(09-01-2012). Confech fija condiciones para admitir federaciones de Ues. privadas al Pleno. http://www.latercera.com/noticia/nacional/2012/01/680-423108-9-confech-fija-condiciones-paraadmitir-federaciones-de-ues-privadas-al-pleno.shtml

Diario El Mostrador.

(19-5-2014) Giorgio Jakson: Nashla no puede ser marionet de sectores radicalizados. http://www.elmostrador.cl/noticias/pais/2014/05/19/giorgio-jackson-naschla-no-puede-sermarioneta-de-sectores-radicalizados/

(23-5-2014). Melissa Sepúlveda: Las juventudes comunistas no participaron en la marcha del 21 de mayo. http://www.elmostrador.cl/noticias/pais/2014/05/23/melissa-sepulveda-las-juventudescomunistas-no-participaron-en-la-marcha-del-21-de-mayo/

\section{Documentos públicos}

CONFECH (2010) Reglamento de Sala. Aprobado en la Sesión Ordinaria de 15 de agosto de 2010 realizada en la Universidad de Santiago de Chile.

Recuperado de: http://movimientoestudiantil.cl/wp-content/uploads/2015/12/2010-Reglamento-de$\underline{\text { Sala-CONFECH-1.pdf }}$

CONFECH (2015) Propuesta de reglamento de Sala. Aprobada en la Sesión Ordinaria de 10 de enero de 2015, realizada en la Universidad Arturo Prat de Iquique.

CONFECH (2011-2015) Síntesis y Actas Sesiones, desde el 16 de abril de 2011 al 12 de septiembre de 2015.

\section{Documentos privados}

Informes de organizaciones políticas sectores centro, izquierda y ultra-izquierda 2011 a 2015. 
Marcelo Mella, Héctor Ríos, Ricardo Rivera, Condiciones orgánicas y correlaciones de fuerza del movimiento estudiantil chileno. Una aproximación desde la Confech (2011-2015) / Organic conditions and strength correlations of chilean student movement. An approach from Confech (2011-2015), Revista Izquierdas, 27, abril 2016, ISSN 0718-5049, pp. 124-160

\section{Entrevistas}

Mella M. Ríos H. y Rivera R. Entrevista a militante organización política perteneciente al sector ultra-izquierda. Santiago, Septiembre 2015.

Mella M. Ríos H. y Rivera R. Entrevista a presidente federación estudiantes perteneciente al sector ultra-izquierda. Santiago, Agosto 2015.

Mella M. Ríos H. y Rivera R. Entrevista a militante organización política perteneciente al sector izquierda. Santiago, Noviemre 2015.

Mella M. Ríos H. y Rivera R. Entrevista a militante organización politica perteneciente al sector centro. Santiago, Noviembre 2014. 